\title{
Spatialité et temporalité de l'épidémie de la Covid-19 au Sénégal. Le processus de production des données sanitaires au regard des discontinuités territoriales
}

Véronique Petit, Nelly Robin et Nelly Martin

\section{(2) OpenEdition}

Édition électronique

URL : https://journals.openedition.org/rfst/1150

DOI : 10.4000/rfst. 1150

ISSN : 2492-3672

Éditeur

Espaces et SOciétés (UMR 6590)

Référence électronique

Véronique Petit, Nelly Robin et Nelly Martin, « Spatialité et temporalité de l'épidémie de la Covid-19 au Sénégal. Le processus de production des données sanitaires au regard des discontinuités territoriales », Revue francophone sur la santé et les territoires [En ligne], Pandémie, crises et perspectives : lectures territoriales de la Covid-19, mis en ligne le 17 juin 2021, consulté le 17 juin 2021. URL : http://journals.openedition.org/rfst/1150 ; DOI : https://doi.org/10.4000/rfst.1150

Ce document a été généré automatiquement le 17 juin 2021.

\section{(i) (2) (2)}

La Revue francophone sur la santé et les territoires est mise à disposition selon les termes de la Licence Creative Commons Attribution - Pas d'Utilisation Commerciale - Partage dans les Mêmes Conditions 4.0 International. 


\title{
Spatialité et temporalité de l'épidémie de la Covid-19 au
} Sénégal. Le processus de production
des données sanitaires au regard des
discontinuités territoriales

\author{
Véronique Petit, Nelly Robin et Nelly Martin
}

Les auteures remercient chaleureusement Jean-Yves Le Hesran, épidémiologue, IRD, UMR MERIT, pour sa relecture attentive et ses conseils précieux.

\section{Introduction}

1 Cet article a pour objectif d'analyser la première vague de la Covid-19 au Sénégal. Le choix a été fait de se concentrer sur la période entre mi-mars et mi-octobre 2020, temporalité incluant la phase de développement, puis de généralisation de l'épidémie et le pic épidémique de la première vague. Notre propos est de montrer que même avec des données qui invitent à la prudence du fait de leur mode de production et de diffusion, et du niveau de l'épidémie au Sénégal, il est possible d'éclairer la dynamique spatio-temporelle de la Covid-19 dans ce pays. Rappelons qu'au terme de neuf mois d'épidémie, début décembre 2020, le Sénégal recense « seulement » environ 16500 cas confirmés, 360 décès et 15800 patients guéris ${ }^{1}$ selon les données du Ministère de l'Action Sociale et de la Santé (MSAS) ${ }^{2}$.

2 Pour cette étude la représentation cartographie a été retenue. Sa qualité heuristique permet de donner de l'ordre à l'incohérence apparente des faits afin de faire émerger des questions essentielles lorsqu'on observe un phénomène inédit et en perpétuelle évolution. Donner à voir un phénomène spatialisé dans l'extension, même réduite, de la carte, c'est permettre à celui qui le visualise de le comprendre plus vite et mieux et de l'appréhender à différentes échelles. Elle rend accessible la complexité des phénomènes 
étudiés et propose une compréhension globale des processus à l'œuvre, souvent appréhendés de manière séquentielle et parcellaire. La carte est outil de recherche, elle est aussi mode de communication. L'objectif est également d'éclairer les prises de décisions politiques et sanitaires et de transmettre les résultats de la recherche sans les altérer et sans susciter par un graphisme inadéquat des erreurs d'interprétation afin de répondre aux demandes d'informations sanitaires internationales (OMS, UA).

Bien que la dynamique épidémique du coronavirus au Sénégal se caractérise par des effectifs réduits, ce qui limite certaines interprétations, l'examiner en s'appuyant sur une approche spatialisée permet de mettre en évidence des constats parfois inattendus sur le processus de diffusion de l'épidémie à partir de l'analyse des cas positifs et des cas communautaires. Les questions soulevées sur la continuité vs discontinuité de la propagation de la Covid-19 sur les territoires et leur temporalité, la diffusion en milieu urbain, et le passage de l'urbain au rural dépassent le simple exemple du Sénégal. Cette étude permet également d'éclairer la gestion de la crise sanitaire, alors que cet État a été donné en exemple pour sa gouvernance sanitaire dans le contexte épidémique ${ }^{3}$, démentant ainsi certains préjugés à l'encontre des États africains ${ }^{4}$ et nourrissant une analyse en termes de résilience des systèmes de santé (OMS 2020, Lo \& al., 2020).

Outre le fait d'être faiblement représentée dans la pandémie, l'Afrique se caractérise par une situation clinique spécifique avec une forte proportion de cas asymptomatiques (80\%), de faibles taux de létalité (inférieurs à $4 \%$ ) et des taux de guérison élevés (supérieurs à $80 \%$ ) (Lo \& al., 2020). Cependant loin d'être similaire sur l'ensemble du continent, la courbe épidémique se caractérise par des profils spécifiques selon les régions. Ce tableau démographique et clinique explique pourquoi les systèmes de santé, en dépit de variations statistiques, des prévisions alarmistes ${ }^{5}$ et des interrogations soulevées lors des premiers mois de la pandémie (Dzinamariara \& al., 2020 ; Gaye \& al., 2020), n'ont pas été submergés par les cas graves de la Covid-19 restés en faible nombre durant la première vague. Plusieurs hypothèses ont été émises afin d'expliquer ces constats (Gaye \& al., 2020 ; Bankole \& al., 2020) : la rapidité des décisions prises par les États suite à la détection des premiers cas (Coulibaly \& al., 2020), la jeunesse de la population africaine et les facteurs de comorbidités associés à l'âge (Diop \& al., $2020: 6$ ), la moindre urbanisation du continent (Nguimkeu \& Tadadjeu, 2020), l'incidence des densités (Bankole \& al., 2020), une possible immunité croisée en raison de la circulation d'autres coronavirus (Lalaoui et al., 2020), une immunité acquise plus forte en raison du contexte épidémiologique dans lequel vivent les populations (Omer \& al., 2020).

5 Compte tenu des données accessibles (absence de données sociodémographiques relatives aux patients telles que le sexe, l'âge, la profession), notre attention se focalisera sur les mobilités et les circulations qui contribuent en partie à expliquer les territoires de l'épidémie et leur évolution. Cette hypothèse sera mise à l'épreuve en privilégiant un jeu d'échelles d'analyses et en descendant à des échelles spatiales plus infra (régions, districts sanitaires, communes) que celles habituellement mobilisées dans les analyses concernant l'Afrique sub-saharienne (Nguimken \& Tadadjeu, 2020).

\section{Le processus de production des données : les limites de l'exercice}

6 Dans cette partie nous présenterons dans un premier temps la typologie des cas de Covid-19, puis les deux sources de données que nous avons mobilisées, avant d'exposer 
la stratégie de dépistage mise en œuvre au Sénégal. En conclusion, nous discuterons les limites des données produites par le MSAS sur lesquelles repose notre analyse.

\section{Classification des cas}

7 La classification des malades de la Covid19, effectuée par le MSAS, se stabilise progressivement avec l'accroissement du nombre de cas et la systématisation de leur enregistrement dans les points focaux des districts sanitaires. Les cas confirmés englobent selon l'Organisation Mondiale de la Santé (OMS) toute personne, symptomatique ou non, avec un résultat biologique confirmant l'infection par le SARS$\mathrm{CoV}-2^{6}$. Ils se déclinent en cas contacts, cas communautaires, cas importés et cas évacués.

\section{Cas contacts}

8 La dénomination des cas contacts et leurs contours restent imprécis dans les premiers temps de l'épidémie comme en témoignent les mentions relevées dans les communiqués du MSAS : « cas contact suivi par nos services ", « cas contact rattaché au patient... ", " cas contact suivi antérieurement répertorié par nos services » et "cas contact direct ». Le Africa Centre for Disease Control and Prevention (CDC) définit le cas contact comme « une personne qui a subi l'une des expositions suivantes au cours des deux jours avant et 14 jours après l'apparition des symptômes d'un cas probable ou confirmé : contact direct avec un cas probable ou confirmé à moins d'un mètre et pendant plus de 15 minutes. Contact physique direct avec un cas probable ou confirmé. Soins directs pour un patient présentant une maladie COVID-19 probable ou confirmée sans utiliser un équipement de protection individuelle approprié $»^{7}$.

\section{Cas communautaires}

9 Les cas dits «issus de la transmission communautaire " apparaissent dans les communiqués à partir du 21 mars 2020 sans qu'une définition précise ne soit apportée par le MSAS. Le terme «communautaire » est porteur d'ambiguïtés puisqu'il semble impliquer un lien sociologique rattachant ces cas à une communauté qui serait identifiée au sein de la société. La tentative d'explications du Pr. D. Ndiaye démontre l'absence de clarté à propos de la transmission communautaire, celle-ci « est notée lorsqu'un cas, au niveau de la communauté, est confirmé alors que l'origine de la contamination n'est pas connue. Cela veut dire qu'il n'a pas été en contact avec un patient connu ni avec un cas importé. Et qu'il s'agit également d'une personne n'ayant pas voyagé dans une zone où il y a la maladie. Donc, l'origine de son infection est à rechercher au sein de la communauté pour essayer de voir d'où provient en réalité la contamination $»^{8}$. La qualification de « communautaire » sous-tend que l'enquête et les dépistages permettant de remonter la chaine de transmission sont réalisés au sein d'une unité sociale qualifiée de "communauté». Les frontières spatiales et anthropologiques de cette construction sociale qui ne sont cependant jamais énoncées, traduisent une pluralité de contextes mettant au défi de trouver une logique commune à ces situations contrastées.

10 En réalité, les cas communautaires renvoient à une situation où la chaine de contamination n'a pas pu être établie sans qu'il soit possible d'en connaître les raisons 
précises. La qualification de "communautaire", pour une partie des cas confirmés, procède donc d'une assignation par défaut par les autorités médicales, ni la source ni les liens épidémiologiques avec d'autres cas n'ayant pu être établis. Notons que si l'on se réfère à la terminologie médicale, la transmission communautaire s'oppose à la contamination nosocomiale 9 , c'est-à-dire à une contamination dans un contexte de soin circonscrit ${ }^{10}$. C'est dans donc dans cette acceptation qu'il faut entendre le terme " communautaire » et non dans un sens anthropologique faussement évident dans un contexte africain.

\section{Cas importés}

11 Selon le CDC Afrique, les cas importés indiquent « uniquement les endroits où tous les cas ont été acquis en dehors du lieu de notification $»^{11}$. En début d'épidémie, des indications liées à la provenance et au profil sociodémographique étaient associées aux cas importés, puisque l'épidémie atteignait le Sénégal principalement par le biais de personnes engagées dans des différentes formes de mobilités (Petit \& Robin, 2020) ${ }^{12}$. Avec la fermeture des frontières, ces cas se raréfiant, ces informations ont disparu. Désormais, il est juste mentionné qu'ils sont identifiés à leur entrée à l'aéroport international Blaise Diagne (AIBD) ou à un autre point d'entrée sur le territoire sénégalais non précisé.

\section{Cas évacués}

12 Cette catégorie renvoie aux patients qui ont été évacués à l'étranger afin d'être pris en charge. L'effectif enregistré n'a pas évolué depuis le début de l'épidémie $(n=1)$ ce qui questionne la qualité du renseignement concernant ces cas.

Les cas contacts représentent en moyenne $70,5 \%$ des cas confirmés, contre $26,5 \%$ pour les cas communautaires et $3 \%$ pour les cas importés ${ }^{13}$, néanmoins ces proportions ont varié au fil du temps.

\section{Sources de données}

14 Afin de reconstruire la dynamique épidémique, nous nous sommes appuyées sur les données produites par le MSAS. Elles sont diffusées à partir de deux supports mis en ligne sur le site du ministère.

\section{Les communiqués quotidiens}

Le MSAS publie quotidiennement un communiqué ${ }^{14}$ présentant différents indicateurs : nombre de tests réalisés, taux de positivité, distribution des cas confirmés en fonction de la typologie présentée préalablement, effectifs des personnes déclarées guéries, des cas graves et des décès. Les cas communautaires sont rapportés à une localisation dont la précision varie en particulier en ce qui concerne la région de Dakar. Si l'on se réfère à la hiérarchisation du découpage administratif, ces cas sont référés tantôt à des communes, parfois des quartiers, d'autres fois à des entités encore plus réduites comme des cités ${ }^{15}$. Cette variabilité s'explique par différents facteurs. D'une part, les adresses des patients sont renseignées par le personnel soignant des points focaux qui complète une fiche de renseignements incluant des données personnelles et cliniques au moment du dépistage. Ces données sont collectées par des médecins, des infirmiers ou des 
sages-femmes, qui sont plus ou moins formés à l'enregistrement d'informations fiables et complètes permettant le suivi des personnes testées. D'autre part, certains patients sont réticents à livrer leurs coordonnées afin d'échapper à une hospitalisation ou une mise en quarantaine.

\section{Les rapports de situation (SITREP)}

Les Rapports de situation, dits SITREP, sont généralement publiés deux fois par semaine ${ }^{16}$. Ils contiennent des données épidémiologiques et des informations relatives aux mesures et aux actions conduites en réponse à la Covid-19. Outre le taux d'incidence, le taux de létalité, la répartition des patients selon le sexe, ils présentent le nombre de nouveaux cas confirmés répartis dans les 79 districts sanitaires du pays ${ }^{17}$. L'information concernant les cas confirmés est donc rapportée à une échelle administrative (districts sanitaires) différente de celle utilisée pour les cas communautaires (échelle infra).

\section{Les échelles d'analyse}

Lors de la saisie de ces informations dans un fichier excel, nous avons recodé et uniformisé les informations relatives à la localisation des cas dits communautaires en prenant la commune comme unité de base ce qui a permis ensuite une agrégation à l'échelle des districts sanitaires. Il s'agit d'assurer une continuité dans l'analyse entre la région de Dakar et les autres régions du pays, et d'établir des comparaisons entre les cas confirmés, contacts et communautaires.

18 Considérer l'épidémie de la Covid19 à différentes échelles spatiales, c'est tenter de repérer la pluralité des situations et la variété des évolutions au sein d'un district sanitaire qui englobe plusieurs communes.

19 La figure 1 représente le taux d'évolution des cas communautaires dans le département de Dakar, entre le 30 juin 2020, date de la levée de l'État d'urgence, jusqu'au 14 octobre 2020, fin estimée de la première vague. L'épidémie de la Covid19 est représentée à deux échelles: celle des districts sanitaires (F.1.1) et celle des communes (F.1.2). L'observation des districts sanitaires donne le sentiment d'une dynamique épidémique uniforme : 3 districts sur 4 présentent le même taux d'évolution. Il s'agit d'une vision tronquée de la réalité. La représentation cartographique à l'échelle des communes révèle la pluralité des situations au sein d'un même district ; dans les districts de Dakar sud, centre et ouest, chacune des communes qui les composent présentent un taux d'évolution distinct. Ainsi, le changement d'échelle éclaire sous un tout autre angle la dynamique épidémique de la Covid19 dans le département de Dakar; il donne à comprendre la complexité de la réalité et favorise l'émergence de nouvelles hypothèses. 
Figure 1 - Évolution des cas communautaires par district sanitaire et par commune entre le 30 juin et le 4 octobre 2020

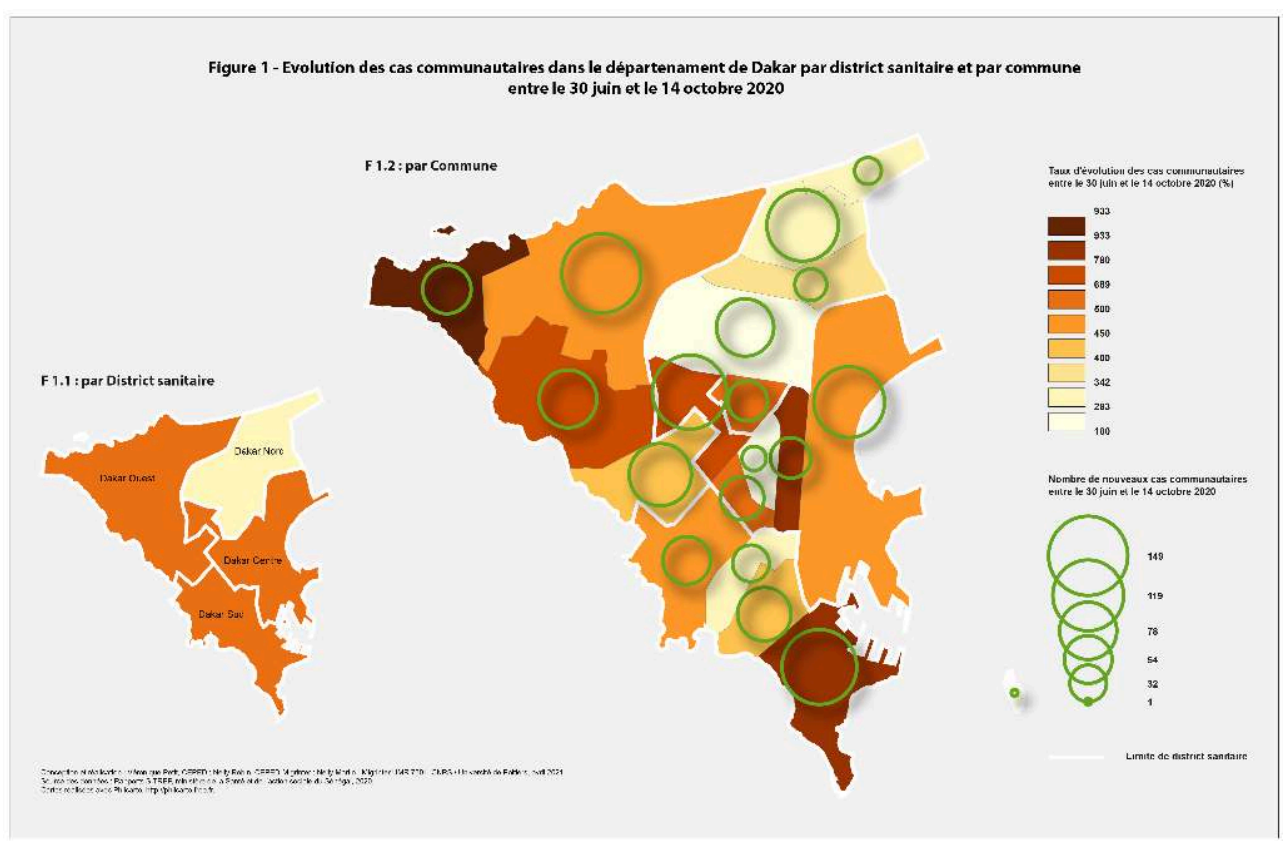

\section{La stratégie de dépistage} importés en provenance d'Italie et de France ${ }^{18}$. Le gouvernement élabore rapidement une riposte afin de réduire la propagation de la maladie et organiser la prise en charge médicale puis le suivi psycho-social des personnes atteintes par la Covid-19. Le Centre des Opérations d'Urgence Sanitaire (COUS) est activé dès le 3 mars. L'arrêté 007782 du 13 mars interdit les manifestations et les rassemblements, restreint les déplacements inter urbains et entre régions, puis le 18 mars les frontières aériennes, terrestres et maritimes sont fermées, de même que les lieux de cultes et d'enseignement ${ }^{19}$. Le 17 avril, le port du masque est rendu obligatoire dans les lieux publics ${ }^{20}$. Enfin, l'état d'urgence est décrété le 24 mars, parallèlement un couvre-feu est instauré de 20 heures à 5 heures. Il sera assoupli le 12 mai, puis levé le 30 juin en même temps que l'état d'urgence. La liberté de déplacement entre les régions est rétablie début juin 2020 sous réserve de certaines précautions sanitaires.

\section{L'évolution du nombre detests}

La production des données utilisées dans cet article est directement liée à la stratégie de dépistage menée par les autorités sanitaires. La faible incidence de la covid-19 en Afrique s'expliquerait en partie par les capacités insuffisantes de tests qui conduiraient à sous-estimer l'épidémie (Kambole \& al., 2020). Certes, cette situation n'est pas spécifique aux pays africains, mais elle invite à rester circonspects dans l'analyse des données puisqu'il s'agit dès lors d'une photographie imparfaite de l'épidémie.

La stratégie de dépistage au Sénégal a évolué avec la propagation de l'épidémie et l'intensification des moyens dédiés à la riposte, on peut donc émettre l'hypothèse raisonnable que les conditions du dépistage ne sont pas identiques sur l'ensemble du 
territoire et au fil du temps. Les autorités politiques et sanitaires ont peu explicité les motivations et les indicateurs qui orientaient leurs décisions en matière de stratégie de dépistage. Aucune information permettant de préciser les circonstances qui ont présidé à la décision de la passation d'un test ne sont disponibles.

\section{Un élargissement du dépistage}

Les autorités sanitaires mettent rapidement en œuvre une stratégie de dépistage. La réalisation des tests est d'abord confiée à l'Institut Pasteur de Dakar (IPD), auquel est adjoint fin mars l'Institut de Recherche en Santé de Surveillance Epidémiologique et de Formation (IRESSEF) afin de renforcer la capacité de dépistage alors que le nombre de cas s'accroit. Durant les premières semaines, le nombre de tests PCR quotidiens ne dépasse pas l'effectif de 500, il faut attendre début mai pour que celui-ci atteigne 1000 tests. Par la suite ce chiffre oscillera entre 900 et 1600 , avec deux périodes de pointe : les trois premières semaines de juin : période qui correspond à l'assouplissement des mesures, puis entre le 5 et 15 août période qui suit la Tabaski. Durant ces phases de pointe, environ 1900 tests journaliers sont effectués, avant de retomber sous la barre des 1400 tests par jour (figure 2).

Figure 2 - Nombre de tests Covid-19 réalisés au Sénégal (du 9 mars au 14 septembre 2020)

Figure 2 - Nombre de tests Covid-19 réalisés au Sénégal entre le 9 mars et le 14 septembre 2020

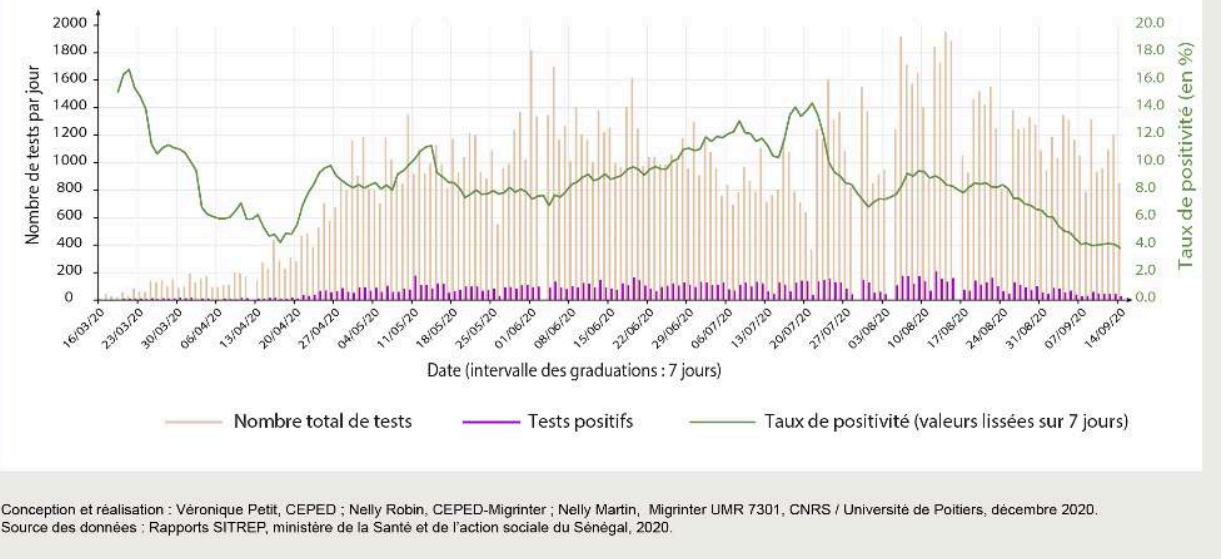

Durant la période où les premiers cas se déclarent, l'IPD détache un laboratoire mobile en mars à Touba, la ville sainte de la communauté mouride, puis un second en avril à Kolda à proximité des frontières sud du Sénégal. Il s'agit d'améliorer la rapidité du dépistage en se rapprochant des populations dans une région extérieure à celle de Dakar. Dans une première phase, en avril, des voix appellent à un dépistage " massif $»^{21}$ afin d'éviter un confinement général. Mi-avril, il est question de tests rapides et bon marché2 ${ }^{2}$, mais ces annonces n'aboutissent pas. A. Bousso (directeur du COUS) admet "que le Sénégal n'a pas les moyens de tester l'ensemble de la population » et mise par conséquent sur une "stratégie de diagnostic consistant à suivre les contacts à haut risque, les personnes suspectes $»^{23}$. Ce changement s'explique par une double nécessité, celle d'avoir une "stratégie dynamique " qui s'adapte à l'épidémie et celle de devoir gérer la capacité des laboratoires et les stocks de réactifs ${ }^{24}$. 


\section{Un dépistage plus ciblé}

25 désormais effectués en priorité sur les cas symptomatiques ou présentant des comorbidités ou âgés de plus de 50 ans. Cette décision suscite des débats à propos de la significativité des statistiques produites et du choix supposé de l'immunité collective. Cette stratégie négligerait le risque de contamination lié aux personnes asymptomatique ${ }^{25}$ et aux cas communautaires dont l'origine de la contamination reste inconnue. M.L. Ly la qualifie de "vision coupable ${ }^{26}$. Il dénonce le relâchement du suivi des cas contacts, le recul concernant le diagnostic post-mortem et l'illusion qu'entretient la décentralisation du dépistage, car elle n'améliore ni les délais de prélèvement ni n'accroît le nombre de tests. De plus certaines populations refusent tout dépistage et nient l'existence de la maladie ${ }^{27}$.

Avec l'émergence de pôles épidémiques secondaires dans les régions, une décentralisation du diagnostic est mise en place avec des laboratoires à Kédougou, Tambacounda, Matam et Thiès ${ }^{28}$. La réouverture de l'espace aérien impose aux voyageurs un test $\mathrm{PCR}$ précédant leur départ. La capacité de dépistage est renforcée par l'hôpital Le Dantec et de l'hôpital militaire de Ouakam ${ }^{29}$. Si la stratégie de dépistage dans ses grandes orientations semble définie à l'échelle nationale, force est de constater que sa mise en œuvre est modulée aux échelles régionale et locale.

\section{Les limites du récit de l'épidémie}

La variabilité des niveaux de cas communautaires questionne le continuum entre cas communautaires et cas contacts, puisque derrière cette dichotomie c'est la question de la stratégie de dépistage et de l'établissement de chaines de contamination qui est posée. La période épidémique la plus active, du 31 juillet au 28 août 2020 , se caractérise par une évolution majeure (figure 3) : les cas communautaires répertoriés à l'intérieur du Sénégal (courbe rouge) supplantent ceux enregistrés dans la région de Dakar (courbe bleue). 
Figure 3 - Évolution des cas communautaires au Sénégal (du 19 avril au 14 septembre 2020)

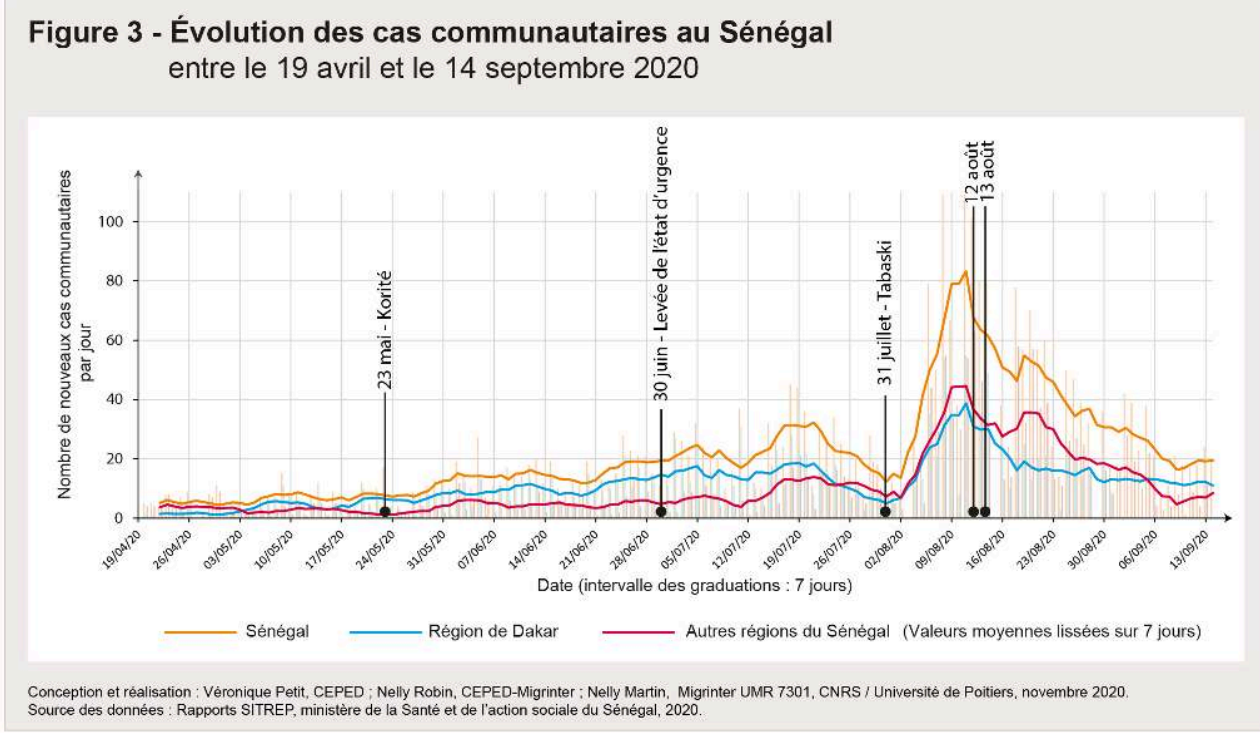

Dans la région de Dakar, l'enquête permettant de remonter la chaine de transmission est sans doute plus facile à conduire qu'en milieu rural. Effectuer un suivi de cas contacts dans un quartier ou un ilot de Dakar, très peuplé, avec des mobilités quotidiennes régulières et dans une zone somme toute limitée, permet une identification plus rapide des cas contacts d'autant que les ressources humaines et techniques en santé sont concentrées dans cette région. A contrario, le suivi de la transmission dans les petites localités et en milieu rural s'avère plus complexe et la notion de communauté peut y être plus extensive. En effet, des personnes originaires de ce lieu peuvent y passer brièvement pour un évènement religieux ou social, puis repartir dans la région où elles résident. Des individus circulant dans le cadre de leurs activités peuvent y faire étape, sans qu'il soit ensuite possible de connaître l'itinéraire qui les a menés là et où il se prolonge.

\section{Le paysage et la dynamique de l'épidémie au Sénégal}

\section{Trois épicentres en dehors de la région de Dakar}

La majeure partie de l'épidémie au Sénégal est localisée à l'ouest d'une ligne qui va de Richard-Toll à Sedhiou (figure 4). La géographie de l'épidémie Covid-19 est une réalité construite dans l'action spatiale ; elle rappelle la macrocéphalie du système urbain du Sénégal, centré sur Dakar, qui progressivement se transforme en région métropolitaine Dakar-Thiès-Mbour-Touba. La répartition démographique entre Dakar et les villes de l'intérieur s'accompagne d'une densification des zones péri-urbaines et rurales, à l'ouest d'une ligne Richard-Toll-Touba-Kaolack (Banque mondiale, 2015). 
Figure 4 - Nombre de cas Covid-19 confirmés au par district sanitaire (au 14 septembre 2020)

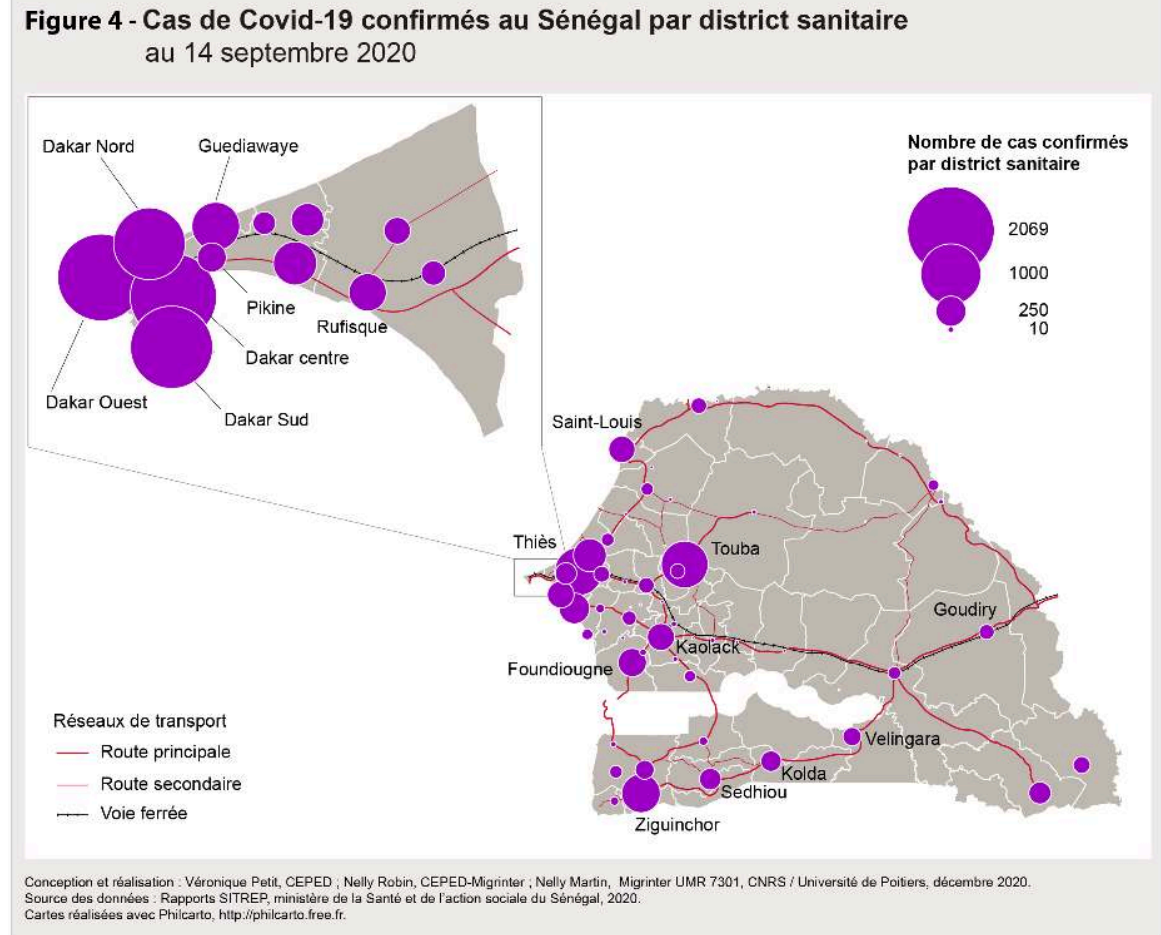

La figure 5 montre l'évolution des cas confirmés de covid-19 entre le $1^{\mathrm{er}}$ mars et le 14 septembre 2020 dans l'ensemble des districts sanitaires du Sénégal, en dehors des districts de la région de Dakar. Parallèlement à cette évolution statistique, nous avons retenu certains événements sociaux, politiques, sanitaires qui peuvent influencer la dynamique de l'épidémie en favorisant les mobilités conformément à notre hypothèse centrale. 
Figure 5 - Évolution des cas de covid-19 confirmés par district sanitaire au Sénégal (du 2 mars au 14 septembre)

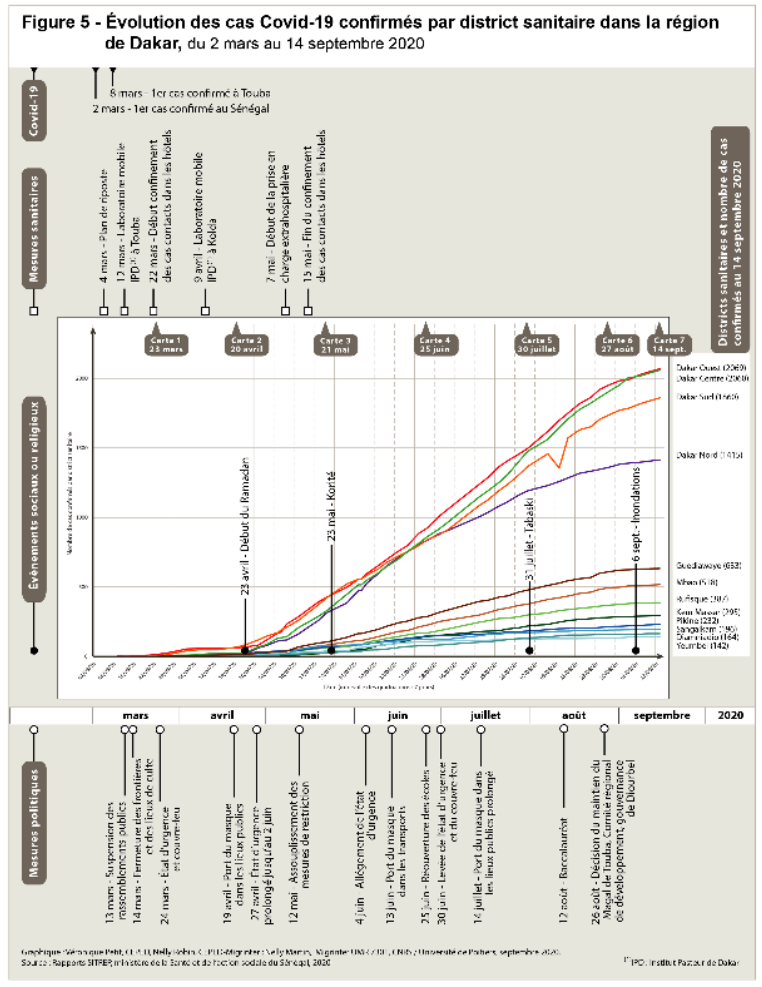

Dakar représente, avec de légères fluctuations au cours de l'épidémie, environ les trois quarts des cas confirmés. Trois foyers secondaires après Dakar apparaissent nettement : Touba, Thiès et Ziguinchor.

\section{Touba, au centre de toutes les attentions}

L'épidémie démarre rapidement dans le district sanitaire de Touba, et plus précisément dans la cité religieuse mouride de Touba ; elle s'y installe avec l'arrivée de migrants de retour d'Italie et d'Espagne ${ }^{30}$. Plusieurs dizaines de familles seront placées en isolement à Touba au cours de l'épidémie. Les procédures de mise en quarantaine sont douloureusement vécues par les familles en raison des attitudes de stigmatisation qui se développent, et des personnes suspectées d'être contaminées refusent d'être dépistées ou fuient les centres de traitement des épidémies (CTE) ou les hôtels où elles sont placées sous surveillance ${ }^{31}$. D'autres personnes dénient l'existence de la maladie et ne veulent pas voir leur activité économique encore plus impactée par la Covid-19.

Rapidement en mars, un laboratoire mobile de dépistage de l'Institut Pasteur est dépêché sur place, un hôpital militaire de campagne est installé, un CTE est construit afin de suppléer au centre de santé de Darou Marnane. La propagation paraît contenue jusqu'au 19 avril, puis la maladie s'installe et croît fortement entre avril et mi-juillet, où elle semble atteindre un plateau ${ }^{32}$.

En raison de la spécificité sociale et politique, du poids démographique de la ville sainte de Touba (2e aire urbaine du pays avec 878586 habitants en 2018), l'épidémie dans le district sanitaire de Touba reçoit une attention particulière, car elle constitue un contexte favorable à une diffusion rapide du virus dans le pays. Lieu de pèlerinage de la confrérie mouride, elle attire constamment, mais plus encore lors des événements 
religieux, des pèlerins nombreux et mobiles. C'est également une ville dont l'économie articule le religieux et le séculier, notamment à travers les réseaux migratoires qui connectent la ville à l'Europe, l'Amérique et l'Asie.

Le déroulement de l'épidémie à Touba soulève deux points. L'analyse de la gestion de l'épidémie au niveau national et local met d'une part en lumière, les relations complexes entre la confrérie mouride et le pouvoir politique autour de la prise de décision des mesures de restrictions sanitaires, la logique sanitaire ne semblant pas pouvoir être complètement dissociée de l'agenda religieux en dépit du caractère laïc de la république sénégalaise. Les prescriptions sanitaires semblent davantage faire sens pour les populations si elles sont adoubées par les autorités religieuses. D'autre part, le rôle joué par des migrants internationaux dans la phase initiale de l'épidémie suscite des réactions de stigmatisation à leur encontre et celle de leur famille, et cela attire davantage l'attention sur les personnes entrant ou se déplaçant à l'intérieur du territoire alors que les frontières sont fermées et les déplacements réglementés. Certains villages interdisent aux « étrangers » d'entrer dans la communauté ou freinent le retour de migrants internes.

\section{Thiès, l'influence des mesures politiques}

La courbe épidémique dans le district de Thiès traduit une évolution très différente de celle de Touba. Jusque fin avril (début du ramadan), la zone semble relativement épargnée, sans doute protégée par les interdictions de déplacements entre les régions. En mai et juin, elle entre dans une seconde phase avec un accroissement du nombre de cas. A partir de la fin juin, se dessine une phase ascendante encore plus marquée. On peut y lire sans doute les effets de l'allègement de l'état d'urgence, puis de sa levée et de la réouverture des écoles. La levée des restrictions sanitaires réactive les mobilités quotidiennes au sein du district sanitaire, ainsi que les circulations importantes entre régions. Situé sur un axe international (Dakar-Bamako), la ville de Thiès est un nœud autoroutier, routier et ferroviaire, qui favorise la convergence des populations puis leur redistribution sur différents axes très empruntés. Ces circulations mettent en lien également les régions les plus densément peuplées du Sénégal et les villes saintes (Tivaouane et Touba) des deux principales confréries musulmanes du Sénégal.

Début septembre, la courbe de Thiès dépasse celle de Touba, ce district devient alors le second pôle épidémique après celui de Dakar. Face à la dégradation de la situation, un laboratoire mobile de dépistage est implanté à Thiès mi-août, alors que les autorités politiques locales réclamaient depuis des mois une décentralisation et un renforcement de la lutte contre l'épidémie.

\section{Ziguinchor, l'impact des cas importés}

38 Le district sanitaire de Ziguinchor constitue le troisième pôle épidémique. Situé en Casamance, dans le sud du pays, il introduit d'autres questionnements liés à la diffusion de la Covid-19. L'épidémie s'invite à Ziguinchor dans la seconde moitié d'avril et durant un mois reste à un niveau peu élevé. A partir de la fin mai, elle entre dans une phase de croissance continue et soutenue jusqu'au 25 août. A partir de cette date, la courbe épidémique s'aplanie et présente un plateau.

39 Les premiers cas identifiés dans le district sanitaire de Ziguinchor datent du 20 mars ; il s'agit d'un ressortissant sénégalais, un migrant vivant en France ${ }^{33}$ et arrivé récemment 
à Ziguinchor. D'autres cas importés, des touristes, sont identifiés à cette période. Miavril, un foyer est détecté dans une école coranique. En mai, des cas importés, des ressortissants mauritaniens et bissau-guinéens sont enregistrés. Début juin, la rentrée scolaire conduit au retour des enseignants en bus dans la région. Certains s'avèrent être positifs ce qui soulève la panique ${ }^{34}$, des villages jusque-là épargnés craignent d'être contaminés par leurs instituteurs. La rentrée initialement prévue le 3 juin est repoussée sine die. La mise en place d'un centre de suivi des cas asymptomatiques est programmée $e^{35}$, alors que dans les médias s'inquiètent de l'entrée de cas en provenance d'autres régions de Casamance (Bignona, Sedhiou) et de Guinée-Bissau.

La situation se dégrade en juillet, la maison d'arrêt et de correction de Ziguinchor devient un cluster ${ }^{36}$. Mi-aout 30 quartiers sur 36 de la commune de Ziguinchor sont touchés. Les cas communautaires se multiplient poussant les autorités locales et nationales à mener des actions de sensibilisation et à renforcer la surveillance des lieux publics en sanctionnant les personnes sans masque. Les deux CTE étant débordés, les patients sont traités à domicile.

\section{Une diversité de districts sanitaires, aux dynamiques contrastées}

Il est intéressant de noter qu'après ces trois foyers épidémiques secondaires apparaissent des districts comme Tivaouane, Mbour et Popenguine sur la petite côte au sud de Thiès, Kaolack sur l'axe Thiès-Tambacounda, et Saint-Louis qui prolonge l'axe Dakar-Tivaouane. Ils sont tous connectés aux districts de Touba, Thiès et Dakar. Ensuite, apparait un ensemble de districts sanitaires situés en Casamance (Kédougou, Sedhiou, Kolda, Bignona, Velingara) ${ }^{37}$, ce qui pousse à s'interroger sur les dynamiques particulières au sein de cet espace, les relations avec d'autres régions du pays et les interactions avec les pays frontaliers.

Ces évolutions spécifiques légitiment l'approche spatiale, elles posent de fait la question des modes de transmission et de circulation du coronavirus. Ces courbes interrogent également les modes de gestion politique et sanitaire différenciés à l'échelle des districts sanitaires, certains districts sanitaires semblent avoir bénéficié d'une approche par cluster contrairement à d'autres. Cette distinction s'observe par exemple dans la région du Sénégal oriental; l'épidémie qui débute mi-mai à Sedhiou, Kolda et Velingara est très vite contenue ; à l'inverse, Saraya connaît une évolution exponentielle à partir du mois d'août qui reste très active encore octobre 2020.

\section{Dakar, une dynamique épidémique qui réinterroge les idées reçues}

Après avoir mis en évidence la pluralité des évolutions de l'épidémie dans les régions à l'exception de celle de Dakar, attardons-nous sur les spécificités de cette dernière. La région de Dakar est le pôle épidémique prépondérant du pays puisqu'il regroupe environ $75 \%$ des cas confirmés au cours de la période étudiée. La figure 6 met en lumière la dynamique spécifique des districts sanitaires de l'agglomération de Dakar par rapport aux autres régions du pays. 
Figure 6 - Évolution des cas de covid-19 confirmés par district sanitaire dans la région de Dakar (du 2 mars au 14 septembre)

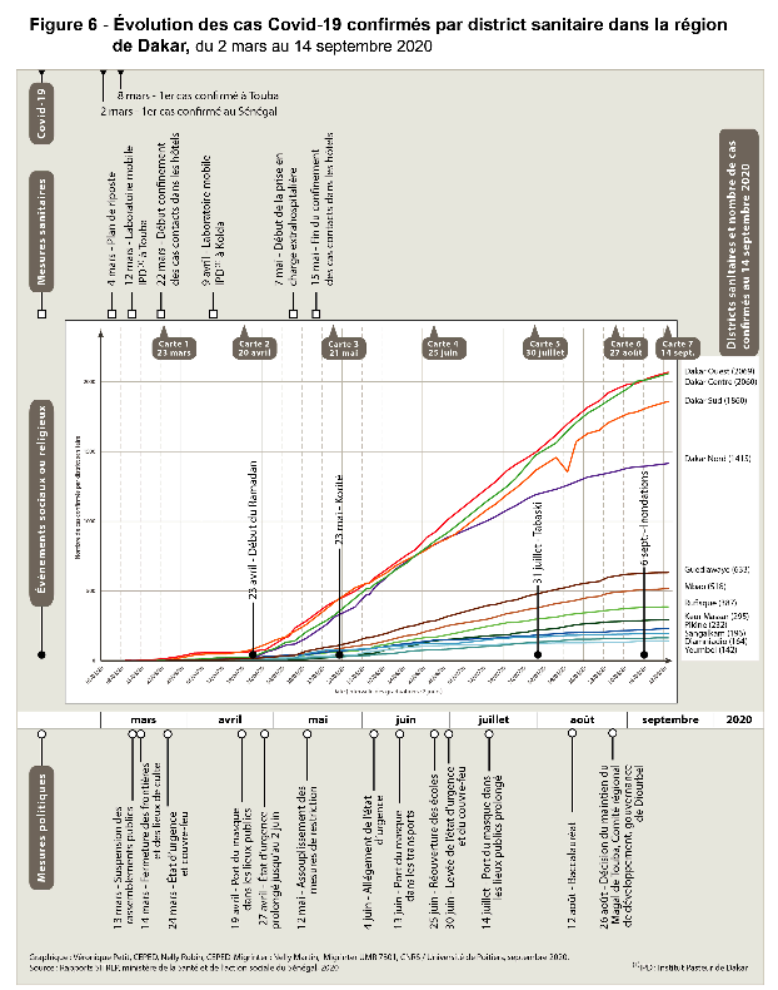

\section{Les disparités entre Dakar et ses banlieues}

Les courbes s'affichent de manière parallèle, même si des rythmes de croissance les distinguent. L'épidémie est centrée sur le département de Dakar ; les districts sanitaires de Dakar ouest, centre, sud, nord (figure 7) ${ }^{38}$ réunissent à eux seuls 7404 cas sur 15.640, soit $51 \%$ de l'ensemble des cas confirmés à la mi-septembre. L'épidémie y démarre plutôt que dans les autres districts sanitaires, d'abord lentement, puis de manière plus spectaculaire à partir de la fin avril où elle s'y installe et s'y développe. Le district de Dakar nord connait cependant un rythme de croissance moins soutenu et semblant s'infléchir à partir de la mi-août. Les autres cas confirmés se répartissent ensuite dans des districts localisés dans les banlieues de Dakar puis dans des localités qui les jouxtent, celles-ci formant de plus en plus un continuum urbain qui ne cesse de se densifier compte tenu de l'évolution de l'immobilier dans la capitale et des dynamiques démographiques (Figure 8). Ces districts sont placés sur les axes routiers et autoroutier qui relient Dakar au nouveau pôle économique de Diamniadio à proximité de l'aéroport international, et aux villes de Thiès et de Touba. Les courbes semblent montrer que la dynamique de l'épidémie dans les districts sanitaires de la région de Dakar est moins impactée par les événements sociaux, politiques et sanitaires que ce qui a été précédemment observé dans les autres régions. L'explication est peut-être à rechercher dans les spécificités du contexte de cette région. 
Figure 7. Districts sanitaires du département de Dakar

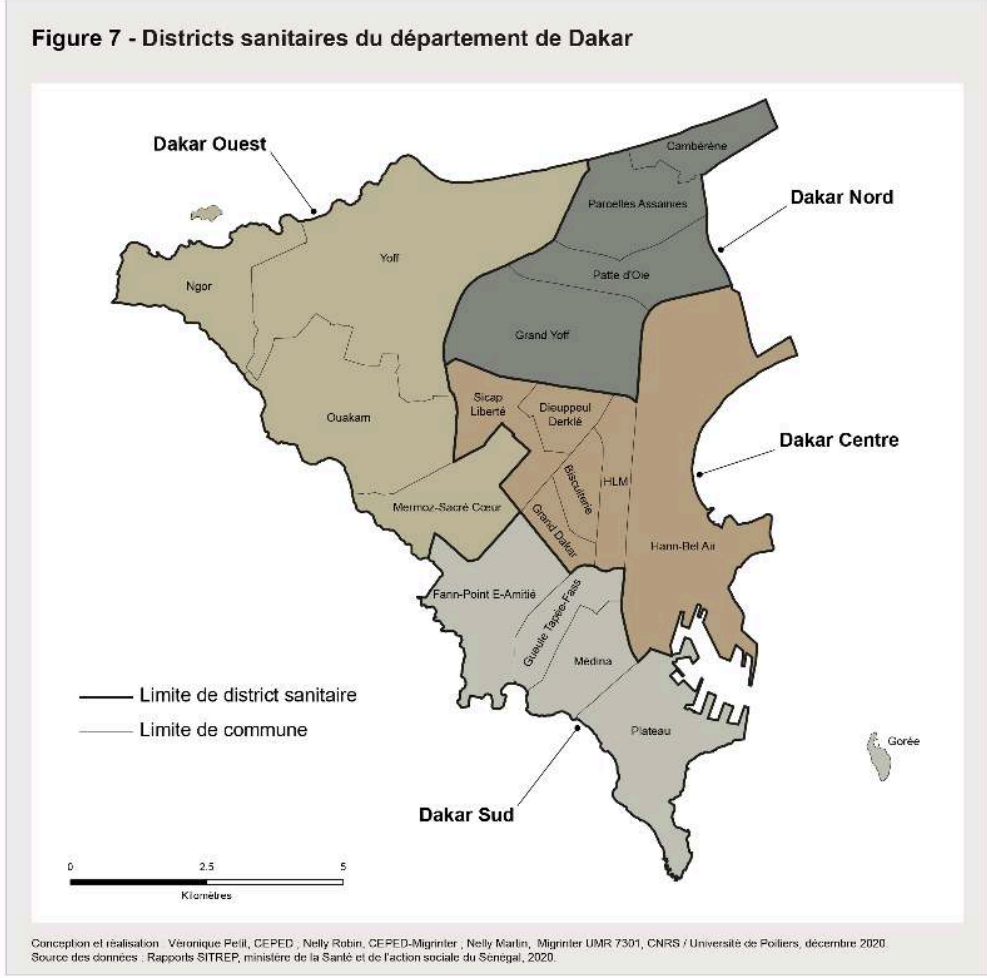

Figure 8 . Districts Sanitaires de la région de Dakar

Figure 8 - Districts sanitaires de la région de Dakar

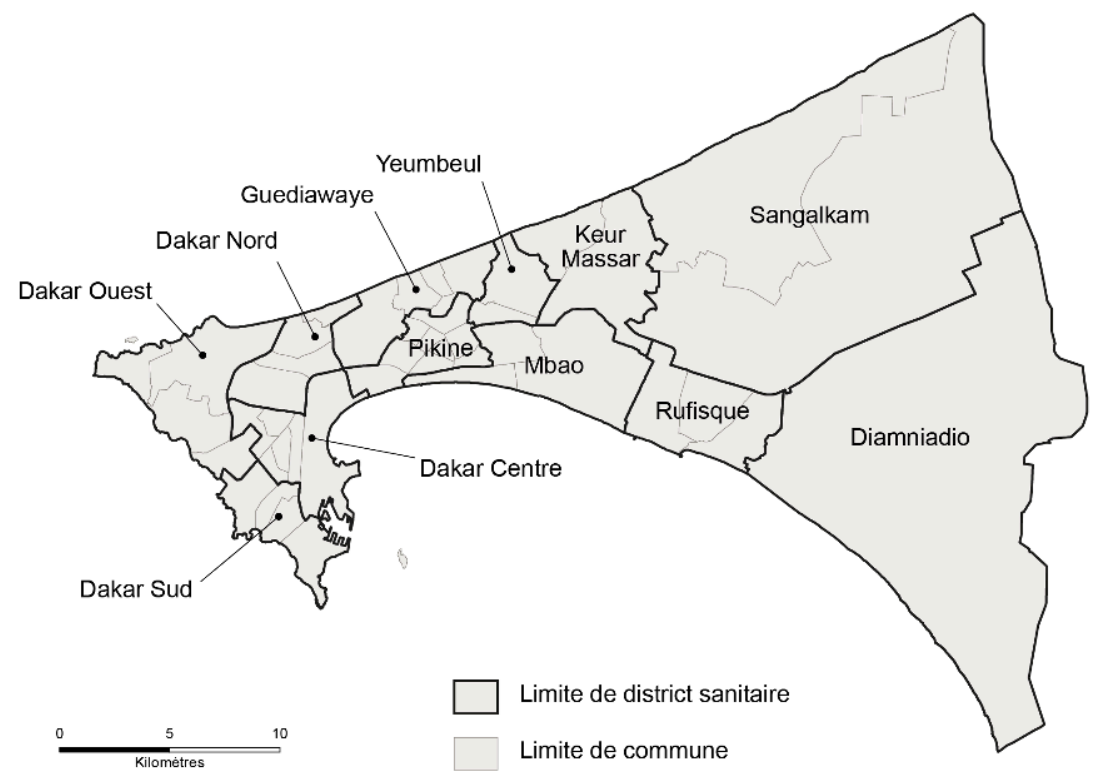

Conception et réalisation : Verronique Petit, CEPED ; Nelly Robin, CEPED-Migrinter ; Nelly Martin, Migrinter UMR 7301, CNRS / Université de Poitiers, décembre 2020

La dynamique démographique de la région se caractérise par de fortes densités de population. Si la densité moyenne du pays est de $85 \mathrm{hab}$. $/ \mathrm{km}^{2}$, elle varie à l'intérieur de 
cette région entre $370 \mathrm{hab} . / \mathrm{km}^{2}$, à Diamniadio à $67759 \mathrm{hab} . / \mathrm{km}^{2}$, à la Biscuiterie (commune du district sud de Dakar) (ANSD, repère statistique $n^{\circ} 6,2020$ ). Si on descend au niveau des ménages, d'après les données du dernier recensement en 2013 (ANSD, 2014), 72,1 \% de la population résidant dans les ménages ordinaires vivent dans des logements dits "surpeuplés ». L'indice de surpeuplement signifie que les personnes vivent à deux ou plus dans un logement où le nombre de pièces est insuffisant au regard de la taille de leur ménage. Dans ce contexte, il est très difficile de respecter de manière stricte les règles de distanciation physique.

\section{Le département de Dakar : des univers sociaux interconnectés}

Les districts sanitaires du département de Dakar sont beaucoup plus touchés par l'épidémie Covid-19 que ceux des départements de Guediawaye, Pikine et Rufisque qui appartiennent à « un espace de contact et de transition entre l'espace urbanisé et les espaces ruraux périphériques » (ANSD 2014) et accueillent une majorité de populations de catégories économiques modestes.

Malgré la diversité des situations résidentielles et la pluralité des mondes sociaux, les districts sanitaires du département de Dakar connaissent des évolutions symétriques jusqu'à la levée de l'état d'urgence et du couvre-feu (30 juin). Ensuite, l'épidémie de la Covid-19 évoluent selon trois tendances :

Une croissance soutenue dans les districts sanitaires de Dakar ouest et de Dakar centre

Les deux districts sanitaires les plus touchés par l'épidémie de la Covid-19 sont ceux qui présentent la plus grande disparité socio-spatiale. On y trouve des quartiers très denses, habités par des populations aux revenus modestes, et des quartiers résidentiels avec une forte proportion de classe moyenne supérieure ou de classe aisée. Dans le district sanitaire de Dakar ouest, à Ngor et Yoff, les villages traditionnels de pêcheurs jouxtent des ilots résidentiels de luxe. Le district de Dakar centre présente également des situations très contrastées : un quartier populaire caractérisé par un fort taux d'occupation des logements, Grand Dakar, le village de pêcheurs de Hann (Yarakh) avec un ordonnancement de l'habitat souvent anarchique, et un quartier résidentiel autour d'un grand complexe scolaire, fréquenté par les enfants de classes moyennes supérieures.

\section{Un ralentissement dans le district sanitaire de Dakar sud}

Le district sanitaire de Dakar sud, où l'épidémie ralentit quelque peu à partir du mois de juillet, réunit le centre historique (Plateau-Médina) et le péricentre (Fann-Point EAmitié) de Dakar. Dans les quartiers du Plateau et de la Médina, « les densités sont plus fortes qu'ailleurs en raison notamment d'un habitat plus vertical mais aussi plus exigu qui explique en partie de forts taux d'occupation des logements » (Lessault \& Imbert, 2013). Dans le prolongement, les quartiers du Point $\mathrm{E}$ et de Fann-résidence sont le domaine des villas luxueuses réservées à l'élite de la société dakaroise.

\section{Une stabilisation progressive dans le district sanitaire de Dakar nord}

Le district sanitaire de Dakar nord, où le nombre de cas Covid-19 confirmés est le moins élevé du département, appartient à la proche banlieue. C'est le domaine des quartiers 
populaires, situés sur l'axe d'extension de l'agglomération dakaroise. Parmi eux, Grand Yoff est la commune la plus peuplée du département de Dakar ; sa population connaît un taux de croissance spectaculaire, soit plus $44 \%$ entre 2002 et 2013 (ANSD 2014). On y observe une grande disparité spatiale entre la partie traditionnelle de Grand-Yoff et les nouveaux quartiers plus aisés. A proximité, les Parcelles Assainies, créées au début des années 70, par la Banque mondiale, pour désengorger le centre-ville de Dakar et ses environs, accueillent aujourd'hui une population très hétérogène du point de vue de leur composition socioprofessionnelle. Ce district Dakar nord est celui qui présente le fond socio-spatial le plus diversifié.

\section{Une hypothèse d'hétérogénéité sociale à approfondir}

51 Ce panorama montre qu'aucun district sanitaire ne présente un contexte socio-spatial uniforme.

Un contexte socio-spatial contrasté élargit le spectre de contaminations dans un quartier

Les districts sanitaires qui enregistrent les effectifs les plus élevés de Covid-19 sont ceux qui réunissent les situations socio-économiques et résidentielles les plus contrastées. Cette hétérogénéité sous-tend des interactions sociales et des mobilités d'intensité inégale. Les quartiers populaires, et notamment les villages de pêcheurs, se caractérisent par une grande promiscuité, à l'échelle de la famille et du voisinage. Les populations des quartiers résidentiels bénéficient d'une distanciation physique plus grande, mais leur mode de vie favorise des mobilités plus fréquentes et plus étendues, liées à l'activité professionnelle, aux loisirs et à la scolarité des enfants. A leurs mobilités personnelles s'ajoutent celles de leurs employés, dont les activités ont été plutôt reconfigurées qu'interrompues. Ce constat laisse à penser qu'un contexte sociospatial contrasté élargit le spectre de contamination dans un quartier et explique en partie que l'on y observe une activité épidémique plus différenciée qu'ailleurs.

\section{La densité de l'habitat n'est pas suffisante pour expliquer la dynamique de l'épidémie}

53 L'évolution du district sanitaire Dakar sud rappelle également que la densité de l'habitat n'est pas suffisante pour expliquer la dynamique de l'épidémie. La Médina est l'un des quartiers populaires les plus ancien de la capitale. Ses habitants se sont forgés une façon de vivre très distincte, profondément ancrée sur leur lieu de vie. Certes, ils entretiennent des relations étroites avec les "gens du Fleuve " ${ }^{39}$ Sénégal qu'ils accueillent régulièrement, mais eux-mêmes se déplacent peu vers les régions de l'intérieur du Sénégal. Ils se démarquent ainsi de la plupart des habitants de l'agglomération dakaroise. A proximité, le Plateau abrite une forte communauté libanaise dont les pratiques sociales et les mobilités professionnelles sont largement circonscrites à Dakar. Ce substrat social explique certainement en partie que l'évolution de l'épidémie dans le district sanitaire de Dakar sud ait été moins sensible à la levée de l'état d'urgence que celle observée dans les districts sanitaires de Dakar ouest et de Dakar centre où un fort brassage de populations s'opère particulièrement autour de gares routières interrégionales et de grands marchés. 
La pauvreté et la densité de population ne seraient pas les seuls facteurs qui augmentent la contagiosité

Dans la région de Dakar, la fracture épidémique n'est donc pas celle qui était attendue. Les districts sanitaires les plus touchés ne sont pas situés en banlieue, mais dans le département de Dakar où de grandes disparités font jour à partir de la levée de l'état d'urgence et du couvre-feu. Les districts sanitaires les plus affectés sont ceux qui présentent une double caractéristique : un habitat très hétérogène, du plus informel au plus résidentiel, et des populations qui ont un niveau de revenus très inégal. Ainsi, la pauvreté et la densité de population ne seraient pas les seuls facteurs qui augmentent la contagiosité. L'environnement socio-spatial semble peu impacter le risque de diffusion du virus qui est principalement déterminé par le dynamisme des interactions sociales tous milieux confondus.

\section{Spatialisation et temporalités}

La figure 9 traduit les temporalités de la dynamique spatiale de la Covid19 au Sénégal et révèle l'influence des mesures politiques, de la stratégie sanitaire et des interactions sociales sur la diffusion de l'épidémie ou son contrôle.

Figure 9. Répartition spatiale des nouveaux cas de Covid-19 confirmés au Sénégal par district communautaire (du 9 mars au 28 septembre 2020)

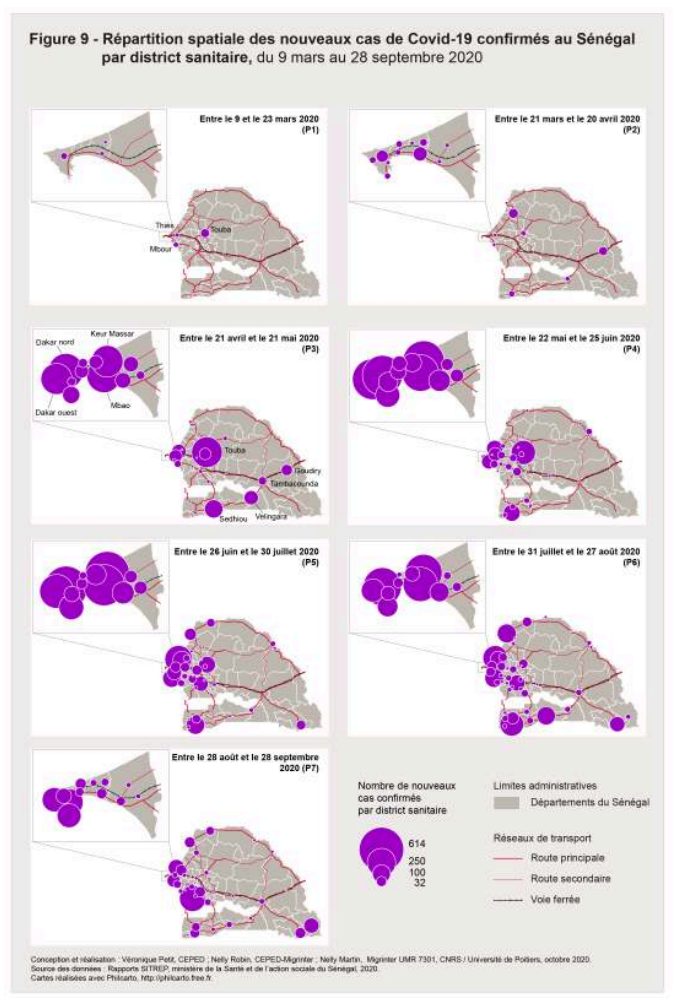

\section{Les territoires initiaux de l'épidémie}

L'agglomération dakaroise, le binôme Thiès-Mbour et la ville sainte de Touba apparaissent comme les trois territoires initiaux de l'épidémie Covid-19 au Sénégal 
(figure 9, Période 1 (P1) et Période 2 (P2)). Ces centres urbains sont interconnectés par un réseau autoroutier. Les échanges sont quotidiens, animés par des mobilités domicile-travail, des circulations commerciales et des déplacements religieux.

\section{Renforcement de la vigilance aux frontières}

Fin avril 2020, un nouvel axe de contamination apparaît au Sud du Sénégal (figure 9, P3), le long d'une diagonale reliant les villes de Sedhiou, Vélingara, Tambacounda et Goudiry, situées au carrefour de trois pays : la Gambie, la Guinée Bissau et la Guinée Conakry. Cette situation exceptionnelle favorise les échanges transfrontaliers. Des marchés hebdomadaires, les loumas ${ }^{40}$, s'égrènent le long des axes routiers et des frontières. L'effervescence commerciale caractérise cette marge frontalière (Fanchette \& Le Renard, 1997).

Le premier cas de Covid-19 répertorié dans cette région est importé. Il s'agit d'une commerçante guinéenne qui souhaite se rendre au marché de Diaobét ${ }^{41}$. Les mobilités transfrontalières, favorisées par le développement des motos-taxis, participent activement à la diffusion du virus. Les lieux de détection des premiers cas de Covid-19 $9^{42}$ rappellent la porosité des frontières et les dynamiques sociales à l'œuvre : il s'agit de Kalifourou, poste frontalier entre la Guinée Conakry et le Sénégal, et de MédinaGounass $^{43}$, ville sainte de la confrérie soufie tidjane.

La stratégie visant à rompre les chaînes de transmission est la même dans les districts de Sédhiou, Vélingara, Tambacounda et Goudiry. Elle associe l'isolement des cas positifs, avec une prise en charge extrahospitalière des cas asymptomatiques simples ${ }^{44}$ et une surveillance renforcée des frontières. Des campagnes de communication et de nouveaux moyens visant la prévention et le contrôle des infections sont déployés aux postes frontière ${ }^{45}$. L'OIM développe un Plan stratégique de Préparation et de Riposte (PSPR) ${ }^{46}$ pour la période février-décembre 2020 en renforçant les 75 points d'entrée officiels dans le pays. Seul l'aéroport international AIBD dispose de procédures opérationnelles normalisées (PON) et d'un plan d'intervention pour les urgences de santé publiques (PIUSP), les autres points d'entrée ne disposent pas des capacités pour détecter et notifier les cas possibles de Covid-19. L'OIM apporte son soutien au gouvernement dans la mise en œuvre du Cadre de Gestion de la Santé, des Frontières et des Mobilités (GSFM), et avec d'autres partenaires, renforce les capacités aux points d'entrée. Les 65 points d'entrée prioritaires sont identifiés. En Casamance, 15 points d'entrée dans les régions de Sédhiou (2), Kolda (8) et Ziguinchor (5) ont vu leurs compétences et équipement accrus. Bien que le Sénégal ait fermé ses frontières, en raison de leur porosité, de la dépendance des populations de part et d'autre, du déficit de ressources en force de défense et de sécurité de nombreuses infractions ont été constatées.

Parallèlement, afin d'inciter les «Jakartmen » à respecter l'état d'urgence qui prévoit l'interdiction des déplacements interrégionaux et internationaux, les autorités locales leur ont attribué une aide financière ${ }^{47}$. Ce dispositif basé sur une gestion par cluster et un contrôle strict des frontières, a été appliqué avec rigueur par les autorités locales et a permis de juguler l'épidémie (figure 9, P4). 


\section{Les effets de la levée de l'état d'urgence}

Début juin, le Ministre de l'Intérieur annonce « l'assouplissement de l'état d'urgence $»^{48}$ ce qui se traduit par la levée des restrictions de transports sur l'étendue du territoire national. Cette décision favorise la circulation du virus le long des principaux axes routiers. L'épidémie de la Covid-19 atteint Ziguinchor, capitale régionale de la BasseCasamance (figure 9, P4).

\section{Le retour en classe des enseignants}

62 Avec l'annonce de la réouverture des classes (26 mai) et la levée de l'état d'urgence (30 juin), le risque épidémique se déploie sur l'ensemble du territoire. La région du Fleuve Sénégal jusqu'alors épargnée est à son tour touchée (figure 9, P5). 19000 enseignants ont dû se déplacer, leur retour vers les établissements scolaires ayant été organisé par les ministères de l'Éducation Nationale et des Transports. Mais finalement, la réouverture des classes, prévue le 2 juin, est reportée sine die la veille. Cette décision est prise après l'identification de dix nouveaux cas Covid-19 au sein du corps enseignant en Casamance : «En rouvrant les écoles dès maintenant, nous risquions de voir exploser les foyers de contagion dans l'ensemble des régions. Nos structures de santé commencent à être débordées, c'est un risque que nous ne pouvions pas prendre ", reconnaît alors une source gouvernementale ${ }^{49}$.

\section{Les libertés de circulation retrouvées}

Tout comme Touba et Thiès, le district sanitaire de Ziguinchor constitue une zone attractive pour toute la région en raison de sa position stratégique. La ville est un carrefour routier sur un axe nord sud reliant Kaolack-Bignona-Sao Domingos en Guinée Bissau, ou Kaolack, Banjul en Gambie-Bignona-Ziguinchor, et d'ouest en est Capskirring-Oussouye-Ziguinchor-Kolda-Velingara-Tambacounda. De plus, elle est située le long du fleuve Casamance (activités portuaires, commerciales, ferry, tourisme), elle bénéficie de liaisons aéroportuaires, de la présence d'une université et de structures de santé. Cette attractivité dépasse le Sénégal du fait de sa proximité avec la Gambie et la Guinée Bissau, puis plus loin de la Guinée. Les populations dans cette région transfrontalière ont l'habitude de circuler librement au gré d'échanges économiques, d'activités sociales et de pratiques thérapeutiques (Petit 2019). La porosité de la frontière et ces habitudes ancestrales nourrissent le brassage des populations. La fermeture le 14 mars 2020 des frontières terrestres et maritimes bouleverse ce mode de vie.

Le 30 juin 2020, l'état d'urgence et le couvre-feu sont levés afin de "reprendre toutes (les) activités productives pour remettre pleinement ( $\left.l^{\prime}\right)$ économie en marche $»^{50}$. Les circulations entre les régions reprennent. Le réseau des villes secondaires, carrefours routiers et commerciaux, structurent la diffusion spatiale du virus. La progression de l'épidémie suit les axes Mbour-Kaolack, Thiès-Touba, Thiès-Saint-Louis et les routes transgambiennes (P5). Kaolack, Khombole, Mecké, Bounkiling et Bignona, où transitent les personnes et les marchandises, s'affirment comme de nouveaux foyers épidémiques. La ville de Kaolack est une plaque tournante du commerce entre la Gambie et le Sénégal ; son marché est l'un des plus importants du pays. Des commerçants et des éleveurs venus de tout le Sénégal font étape à Khombole avant de rejoindre le marché 
hebdomadaire de Touba-Toul. Mecké comme Bounkiling, situés au carrefour de plusieurs axes routiers, sont des lieux d'échanges qui servent de lien entre les centres urbains et le milieu rural. Et, Bignona se situe à l'intersection des deux routes qui relient Ziguinchor à Banjul (Gambie) et à Dakar. Dans ces localités, les premiers cas confirmés sont liés aux mobilités des commerçants, des enseignants, des ouvriers temporaires du bâtiment et des transporteurs.

\section{Les sociabilités réanimées}

Durant cette période dans la région Dakar, la levée de l'état d'urgence et du couvre-feu réanime les sociabilités et les activités qui s'étaient éteintes. Cela provoque une augmentation des nouveaux cas Covid-19 confirmés dans le département de Dakar et une accélération de la diffusion de l'épidémie vers la banlieue (figure 9, P6). Les districts sanitaires de Keur Massar, Mbao, Rufisque et Diamniadio enregistrent les taux d'évolution les plus élevés; ces villes sont étroitement connectées à Dakar par un réseau de transport très dense qui structure les mobilités quotidiennes domiciletravail.

D'intenses échanges relient les districts de Dakar aux banlieues et aux villes situées audelà. Dakar concentre $55 \%$ du PIB et $80 \%$ des entreprises modernes y sont localisées. Alors que la population reste encore pour moitié rurale, l'économie urbaine est le moteur de la croissance. Dakar concentre les activités économiques modernes génératrices d'emplois et de revenus, tandis que les zones extérieures constituent davantage des cités dortoirs où réside une main-d'œuvre quotidiennement contrainte de recourir aux moyens de transports collectifs pour rejoindre son lieu d'activité.

Selon l'Enquête ménage sur la mobilité, le transport et l'accès aux services urbains dans l'agglomération de Dakar (EMTSUDD 2015) sur les 7204826 déplacements quotidiens, $70 \%$ sont assurés à pied et $30 \%$ en mode motorisé. Parmi ceux-ci, $88,5 \%$ sont effectués en transports collectifs. Les pratiques d'intermédiation sociale autour et dans les transports collectifs constitue une dimension favorable à la circulation du coronavirus en raison de la multiplicité des groupes sociaux qui sont ainsi mis momentanément en contact.

68 Fin juillet 2020, le département de Dakar concentre environ $60 \%$ des nouveaux cas Covid-19 confirmés au Sénégal. Par la suite, la diffusion spatiale du virus conduit à un équilibre entre Dakar et le reste du pays.

\section{Une reprise des mobilités et des échanges économiques}

L'expansion spatiale de l'épidémie Covid-19 s'élargit après la Tabaski (Aïd el-Kebir), fêtée le 31 juillet (figure 9, P6). Considérée comme la fête religieuse la plus importante de l'année, la «fête du mouton» engendre de multiples circulations qui mettent en contact des groupes sociaux très différents dans les transports, les espaces de commensalité qui y sont associés et les lieux de négoce. Tout d'abord dans sa phase préparatoire, car il faut pourvoir à l'approvisionnement alimentaire et à l'achat de nouvelles tenues vestimentaires ce qui implique de se rendre sur divers marchés et foirails. Ensuite, les réunions de famille à cette occasion poussent de nombreux migrants internes à regagner leur région d'origine, dans les villes et les villages. L'appel du Ministre de la santé, A. Diouf Sarr, à fêter la Tabaski sur place, là où on réside, ne 
réussit pas à modifier cette tradition coutumière à laquelle la population est fortement attachée.

La figure 9 (P6) traduit une intensification des circulations et une amplification des échanges dans les nœuds stratégiques, lieux de convergence et de redistribution des populations. L'évolution spatiale observée dans les territoires du bassin arachidier (figure 9, P6), comme en Casamance ou dans la région du Fleuve, révèle un déploiement progressif de l'épidémie des pôles urbains vers le monde rural. La propagation du virus autour de Kaolack illustre ces mutations spatiales; il se diffuse progressivement dans les districts sanitaires voisins, et plus particulièrement le long des axes routiers qui relient Kaolack à la Gambie et à la Casamance.

71 Début septembre 2020, Sokone ainsi que Kedougou et Saraya (figure 9, P7) enregistrent à leur tour une forte croissance de l'épidémie. Sokone est une étape « obligée » entre Kaolack et Banjul ; elle abrite un « louma » qui draine des populations de toute la région et de la Gambie voisine. Toutefois l'ampleur et la soudaineté de l'épidémie dans cette ville laisse supposer que d'autres dynamiques sont à l'œuvre. Kedougou, ville frontalière avec le Mali et la Guinée, se situe au cœur d'un bassin minier. Des milliers de personnes venues de toute l'Afrique de l'Ouest participent à cette ruée vers l'or. Saraya est l'un des principaux sites d'orpaillage ; les puits clandestins y sont nombreux et la traite à des fins d'exploitation sexuelle y est pratiquée (Robin \& Saïs, 2018). La position frontalière de ces districts sanitaires et leur attractivité économique renforcent le risque de transmission du virus. L'abondance des pluies la première semaine de septembre a éprouvé les conditions de vie des populations locales : le Plan ORSEC a été déclenché à Sokone ${ }^{51}$ et Kedougou a été coupé du reste du Sénégal plusieurs jours ${ }^{52}$. Cette dégradation de l'environnement sanitaire a inévitablement entraîné un relâchement dans les gestes barrières et peut expliquer l'accélération de l'épidémie dans ces espaces ruraux où le personnel de santé n'a pas été épargné ${ }^{53}$.

72 Ainsi la série de cartes (P1 à P7) qui composent la figure 9 montre sans ambiguïté que la trajectoire de l'épidémie épouse le réseau des nœuds de communication, lui-même étroitement connecté à l'archipel des marchés et aux marges frontalières qui jouent un rôle moteur dans l'économie du Sénégal. Spatialités et temporalités de l'épidémie Covid-19 rappellent que les dynamiques de diffusion du virus sont aussi des dynamiques sociales. Le pic épidémique est atteint les 12 et 13 août 2020, environ 14 jours après la Tabaski. Et fin août, on observe une inversion de la dynamique spatiale : plus de $55 \%$ des nouveaux cas Covid-19 confirmés sont répertoriés en dehors de Dakar. Cette évolution renforce l'hypothèse du rôle des mobilités dans la diffusion du virus, la levée de l'état d'urgence a permis la reprise des échanges économiques et familiaux entre la région de Dakar et l'intérieur du Sénégal.

\section{Conclusion}

Si les temporalités de l'épidémie sont liées aux décisions politiques, les réseaux de communication n'en restent pas moins un élément à prendre en considération dans la diffusion spatiale de la Covid-19. La levée de l'État d'urgence, la rentrée scolaire et la Tabaski constituent les évènements clés de cette dynamique spatio-temporelle, favorisée par une reprise des circulations à différentes échelles. Le triangle DakarThiès-Touba constitue l'épicentre de l'épidémie au Sénégal. Parallèlement, la plaque tournante économique constituée de Kaolack et des villes secondaires du bassin 
arachidier et la diagonale Ziguinchor-Kolda-Vélingara se sont progressivement affirmées comme des réseaux de diffusion actifs de la Covid-19 favorisant la circulation entre le milieu urbain et le milieu rural.

Plus spécifiquement, l'analyse spatiale de l'épidémie Covid-19 au Sénégal invite à déconstruire l'idée selon laquelle une forte activité épidémique serait essentiellement consécutive des conditions de l'habitat. Les dynamiques observées entre les quartiers de la région de Dakar révèlent une plus grande complexité : les quartiers à habitat précaire et les quartiers résidentiels des classes moyennes supérieures partagent une situation épidémique comparable liée à l'intensité des interactions sociales, même si elles relèvent de pratiques différentes. Cela n'exclut pas qu'à monde social égal l'activité épidémique puisse varier comme en témoigne les différences observées entre des quartiers du centre de Dakar et de la banlieue, moins touchée qu'annoncé au début de l'épidémie.

Ainsi, le processus de production des données sanitaires offre une lecture des discontinuités territoriales qui interrogent la politique de dépistage adoptée par les autorités sénégalaises et la nomenclature retenue dans l'enregistrement des cas positifs; derrière l'apparente simplicité de la classification des cas (communautaires, contacts), on devine une hétérogénéité de situations sociales et spatiales. Cette invisibilité du réel limite les hypothèses que peuvent émettre les scientifiques, d'abord liées à la production des données, et traduit des enjeux politiques sous-jacents consubstantiels à la crise sanitaire de la Covid-19.

Cet article interroge les dynamiques temporelles et spatiales lors de la première phase de l'épidémie de la Covid19 au Sénégal. Il éclaire les mécanismes de diffusion du virus sans présager de son intensité ensuite.

\section{BIBLIOGRAPHIE}

ANSD, 2020, Repère statistique de l'environnement d'évolution du Covid-19 au Sénégal, note de synthèse $n^{\circ} 4$. La disponibilité des services de soins de santé au Sénégal, [En ligne], consulté le 15 septembre 2020, http://www.ansd.sn/ressources/publications/ Repere\%20statistique\%20covid_N4_soins\%20de\%20sante\%20et\%20services\%20des\%20SS.pdf ANSD, 2020, Repère statistique de l'environnement d'évolution du Covid-19 au Sénégal, note de synthèse $n^{\circ} 5$. Conditions d'habitat des ménages : éléments d'éclairage en période de pandémie liée au Covid-19, [En ligne], consulté le 15 septembre 2020, http://www.ansd.sn/ressources/ publications/ Repere\%20statistique\%20covid_5\%20\%20Conditions\%20habitat\%20des\%20menages\%20face\%20covid-19_V15062020_VFlast.pdf ANSD, 2020, Repère statistique de l'environnement d'évolution du Covid-19 au Sénégal, note de synthèse $n^{\circ} 6$. Chiffres clé sur la population du Sénégal, [En ligne], consulté le 15 septembre 2020, http://www.ansd.sn/ressources/publications/Repere\%20statistique\%20covid_N6-populationsenegal.pdf 
ANSD, 2020, Repère statistique de l'environnement d'évolution du Covid-19 au Sénégal, [En ligne], consulté le 15 septembre 2020, http://www.ansd.sn/ressources/publications/ Repere\%20statistique\%20covid_maladies\%20chroniques.pdf

ANSD, 2019, Situation économique et sociale du Sénégal 2016 : transport, [En ligne], consulté le 15 septembre 2020 ,

http://www.ansd.sn/ressources/publications/13-SES-2016_Transport.pdf

ANSD, Rapport définitif Recensement Général de la Population et de l'Habitat, de l'Agriculture et de l'Élevage 2013, septembre 2014, [En ligne], consulté le 15 septembre 2020, http:// www.ansd.sn/ressources/rapports/Rapport-definitif-RGPHAE2013.pdf

Ba C.O., Bourgoin J., Diop D., 2018, Sénégal : la fluidité des mobilités internes en réponse aux contraintes locales, In : S. Mercandalli, B. Losch (eds.), Une Afrique rurale en mouvement. Dynamiques et facteurs des migrations au sud du Sahara. Rome : FAO et CIRAD, [En ligne], consulté le 15 septembre 2020, https://agritrop.cirad.fr/588119/1/ID588119.pdf

Ba C.O., Bourgoin J., Diop D., 2018, Les migrations rurales dans la dynamique migratoire sénégalaise. La fluidité des mobilités internes en réponse aux contraintes locales. Rome : FAO et CIRAD, [En ligne], consulté le 15 septembre 2020, http://www.fao.org/3/I9256FR/ i9256fr.pdf\#page=1\&zoom=auto,-134,842

Ba M., Diop M., 2020, Repère statistique de l'environnement d'évolution du Covid-19 au Sénégal, Impact des mesures d'urgence et de prévention sur la propagation du Covid-19 au Sénégal, [En ligne], consulté le 15 septembre 2020, http://www.ansd.sn/ressources/publications/ CovidSN_SIR_DIOP_BA.pdf

Banque Mondiale, 2015, Villes émergentes pour un Sénégal émergent, Revue de l'urbanisation, 126 p, [En ligne], consulté le 15 septembre 2020, http://documents1.worldbank.org/curated/en/ 900681468197983382/pdf/ACS14161-REVISED-FRENCH-WP-P124695-PUBLIC-SenegalUrbanization-Review.pdf

Coulibaly F., Holder G., Vidal L., 2020, "Covid-19, le retour de l'État en Afrique ?", The Conversation, [En ligne], consulté le 10 juin 2020, https://theconversation.com/covid-19-le-retour-de-letat-enafrique-139627

Diallo A., 2018, Changement climatique et migrations humaines au Sénégal : une approche en termes de vulnérabilité du système socio-écologique, Université de Grenoble Alpes (UGA) soutenue le 04/10/2018, [En ligne], consulté le 10 septembre 2020, https://tel.archivesouvertes.fr/tel-01539097

Dzinamarira T., Dzobo M., Chitungo I., 2020, Covid-19: a perspective on Africa's capacity and response, Journal of Medical Virology, [En ligne], consulté le 27 juin 2020, https:// onlinelibrary.wiley.com/doi/full/10.1002/jmv.26159

Diop B.Z., Ngom M., Pougué Biyong C., Pougué Biyong J., 2020, The relative young and rural population may limit the spread and severity of Covid-19 in Africa: a modelling study. BMJ Global Health. [En ligne], consulté le 15 novembre 2020, https://gh.bmj.com/content/5/5/e002699

Fanchette S., 2001, Désengagement de l'État et recomposition d'un espace d'échange transfrontalier : la Haute-Casamance et ses voisins, Autrepart, vol. 19, n³, pp. 91-113.

Fanchette S., Le Renard T., 1997, Relations transfrontalières et Intégration par le bas : la HauteCasamance et ses voisins, Dakar : Orstom Bel-Air, $18 \mathrm{p}$. 
Gaye B., Khoury S., Cene C.W., et al., 2020, Sociodemographic and epidemiological consideration of Africa's Covid-19 response: what is the possible pandemic course? Nature Medecine, June 2020, [En ligne], consulté le $1^{\mathrm{er}}$ juillet 2020, https://www.nature.com/articles/s41591-020-0960-y

Kambole T.O, Omoyeni O.B., Oyebode A.O. et al., 2020, Low incidence of Covid-19 in West Africa sub-region: mitigating healthcare delivery system or matter of time? Journal of Public Health: From theory to practice. [En ligne], consulté le 19 octobre 2020 https://europepmc.org/article/ $\mathrm{pmc} / \mathrm{pmc} 7568012$

Lalaoui R., Bakour S., Raoult D., et al., 2020, What could explain the late emergence of COVID-19 in Africa?, New Microbes and New Infections, [En ligne], consulté le 15 octobre 2020, https:// doi.org/10.1016/j.nmni.2020.100760

Lessault D., Imbert C., 2013, Mobilité résidentielle et dynamique récente du peuplement urbain à Dakar (Sénégal), Cybergéo, $n^{\circ} 662$, [En ligne], consulté le 25 novembre 2020 https:// journals.openedition.org/cybergeo/26146

Lo M., SY A., Yade S., 2020, La Covid-19 en Afrique : bilan d'étape et perspectives, Research paper, Policy Center for the New South, $35 \mathrm{p}$.

Lombard J., 2015, Transporteurs et État sénégalais : une communauté d'intérêts, In Le monde des transports sénégalais, J. Lombard (dir.) Paris, IRD éditions, pp. 113-137. [En ligne], consulté le 27 septembre 2020, https://books.openedition.org/irdeditions/8746?lang=fr

Lombard J., Sakho P., Bruez F. et al., 2004, Les rues de Dakar : espaces de négociation des transports collectifs, Autrepart, 2004/4, n³2, pp. 115-134, [En ligne], consulté le 27 septembre 2020, https://www.cairn.info/revue-autrepart-2004-4-page-115.htm

OMS, 2020, Covid-19 in Africa: from readiness to response, [En ligne], consulté le 9 septembre 2020, http://whotogo-whoafroccmaster.newsweaver.com/journalenglishnewsletter/g65c7ca8gui

Ministère de la Santé et de l'Action Sociale, Plan National de Développement Sanitaire et Social 2019-2028, Dakar, 131 p.

Ndiaye I., 2015, Étalement urbain et différenciation socio spatiale à Dakar (Sénégal). Cahiers de géographie du Québec, vol. 59, n²166, pp. 47-69, [En ligne], consulté le 25 septembre 2020, https://www.erudit.org/fr/revues/cgq/2015-v59-n166-cgq02298/1034348ar.pdf

Nguimkeu P., Tadadjeu S., 2020, Why is the Number of COVID-19 Cases Lower Than Expected in Sub-Saharan Africa? A Cross-Sectional Analysis of the Role of Demographic and Geographic Factors, World Development, [En ligne], consulté le 17 octobre 2020, doi: 10.1016/j.worlddev. 2020.105251

Omer S.B., Yildirim I., Forman H.P, 2020, Herd Immunity and Implications for SARS-CoV-2 Control, JAMA insight, [En ligne], consulté le 30 octobre 2020, https://jamanetwork.com/ journals/jama/fullarticle/2772167?guestAccessKey=c68b3072-6880-4846-9711aff52a80270a\&utm_source=silverchair\&utm_medium=email\&utm_campaign=article_alertjama\&utm_content=olf\&utm_term $=101920$

Petit V., Robin N., 2020, Covid-19 et migrations en Afrique : la réduction des mobilités, une riposte efficace?, The Conversation, publié le 31 mai 2020, https://theconversation.com/ covid-19-et-migrations-en-afrique-la-reduction-des-mobilites-une-riposte-efficace-139283

Petit V., 2019, Circulations et quêtes thérapeutiques en santé mentale au Sénégal, Revue francophone sur la santé et les territoires, [En ligne], consulté le 7 octobre 2020, https:// rfst.hypotheses.org/les-circulations-en-sante-des-produits-des-savoirs-des-personnes-enmouvement 
Robin N., Sais L., 2018, La fabrique des réseaux de traite au Sénégal. Échelles migratoires et situations prostitutionnelles, Outre-Terre, $\mathrm{n}^{\circ} 53$, pp. 67-82.

\section{NOTES}

1. On observe une différence entre les effectifs des cas positifs et les cas guéris, sont comptabilisés comme guéris les personnes qui ont été hospitalisées, soignées puis testée négatives. L'écart s'explique par les décès et les personnes ayant fui l'hospitalisation car elles redoutaient la stigmatisation et de la perte d'activité. Celles-ci n'ont pas été à nouveau testées et donc n'ont pu être officiellement déclarées guéries. Durant leur hospitalisation, les patients sont répartis entre " cas grave pris en charge " et ceux dont « l'état de santé est stable ».

2. Pour une actualisation quotidienne des données, voir le site du Ministère de la Santé et des Affaires Sociales, https://cartosantesen.maps.arcgis.com/apps/opsdashboard/ index.html\#/260c7842a77a48c191bf51c8b0a1d3f6

3. Sont classés 36 pays, dont ceux du G20 et quelques pays en développement qui ont été identifiés par des experts pour leur expérience notable dans la réponse face à la Covid-19, https://globalresponseindex.foreignpolicy.com/methodology/

4. "Coronavirus: l'Afrique au défi de son système de santé » consulté le 3 avril 2020,https://www.lemonde.fr/afrique/article/2020/04/03/coronavirus-l-afrique-faceau-defi-de-son-systeme-de-sante_6035441_3212.html ; «Coronavirus: les experts du Quai d'Orsay redoutent le " coup de trop " qui « déstabilise » l'Afrique », consulté le 3 avril 2020 https://www.lemonde.fr/afrique/article/2020/04/03/coronavirus-lesexperts-du-quai-d-orsay-redoutent-le-coup-de-trop-qui-destabilise-1-

afrique_6035470_3212.html\#xtor=AL-32280270, suite à la note du Ministère de l'Europe et des Affaires Étrangères, 24 mars 2020, note diplomatique intitulée : l'effet pangolin : la tempête qui vient en Afrique.

5. "Covid-19: l'Afrique doit éviter d'arriver au stade de la transmission communautaire, avertit l'OMS " https://news.un.org/fr/story/2020/03/1064302, "Coronavirus: au Sénégal «cela risque d'être une hécatombe», https:// www.nouvelobs.com/coronavirus-de-wuhan/20200325.OBS26585/coronavirus-ausenegal-cela-risque-d-etre-une-hecatombe.html consultés le 20 octobre 2020. «Nouvelles estimations de l'OMS: près de 190000 personnes pourraient mourir de COVID-19 en Afrique si la maladie n'est pas maitrisée ", le 7 mai 2002, https:// www.afro.who.int/fr/news/nouvelles-estimations-de-loms-pres-de-190-000-personnespourraient-mourir-de-covid-19-en

6. définition au 19 octobre 2020

7. UA-CDC Africa, «Pandémie de la Covid-19 : directives sur la recherche de contacts » https://au.int/sites/default/files/documents/38351-docguidance_on_contact_tracing_for_covid-19_pandemic_fr.pdf

8. Consulté le 19 octobre 2020, https://www.seneplus.com/sante/le-pr-daouda-ndiayeexplique-le-processus

9. https://www.dictionnaire-medical.fr/definitions/618-communautaire/

10. https://www.infectiologie.com/UserFiles/File/formation/epilly-trop/ epillytrop2016.pdf 
11. UA-CDC Africa, Bulletin d'information $n^{\circ} 11$, consulté le 19 octobre https://au.int/ sites/default/files/documents/38316-doc-africacdc_covidbrief_31mar20_fr.pdf

12. https://theconversation.com/covid-19-et-migrations-en-afrique-la-reduction-desmobilites-une-riposte-efficace-139283

13. Ministère de la Santé et des Affaires Sociales, Types de transmission, consulté le 19 octobre 2029, https://cartosantesen.maps.arcgis.com/apps/opsdashboard/ index.html\#/260c7842a77a48c191bf51c8b0a1d3f6

14. http://www.sante.gouv.sn/actualites

15. Les cités sont des ensembles de petits immeubles construits par des sociétés étrangères ou sénégalaises pour y loger leurs personnels afin de les rapprocher de leurs emplois localisés à l'intérieur de Dakar.

16. http://www.sante.gouv.sn/search/node/sitrep

17. ANSD, 2020, Enquête Continue sur la Prestation des Services de Soins de Santé (ECPSS 2018), consulté le 19 octobre 2020, https://dhsprogram.com/pubs/pdf/SPA32/ SPA32.pdf .

18. Cheikh Sokhna, «Le Sénégal face au défi du Covid-19 ", consulté le 14 mars 2020 , https://theconversation.com/le-senegal-face-au-defi-du-covid-19-133555

19. https://www.sec.gouv.sn/arr\%C3\%AAt\%C3\%A9-n\%C2\%B0-007782-du-13-mars-2020portant-interdiction-provisoire-de-manifestations-ou-rassemblements

20. https://www.sec.gouv.sn/actualit\%C3\%A9/arr\%C3\%AAt\%C3\%A9minist\%C3\%A9riel-n\%C2\%B0-009137-du-17-avril-2020-prescrivant-le-port-obligatoirede-masque-de

21. «A. Lyane Sow suggère le test massif, pour éviter le confinement général » consulté le 22 avril 2020,

https://www.enqueteplus.com/content/porteurs-asymptomatiques-et-transmissioncommunautaire-de-covid-19-pr-ahmad-iyane-sow

22. «Dakar va produire des tests rapides de dépistage du coronavirus à moins d'un euro ", consulté le 13 avril 2020, https://www.lemonde.fr/afrique/article/2020/04/13/ dakar-va-produire-des-tests-rapides-de-depistage-du-coronavirus-a-moins-d-uneuro_6036469_3212.html

23. «Dr Abdoulaye Bousso, directeur du Centre des opérations d'urgence sanitaire : " Ce n'est pas possible de jouer avec l'opinion sur les chiffres ", consulté le 14 avril 2020, https://www.lequotidien.sn/dr-abdoulaye-bousso-directeur-du-centre-des-operationsdurgence-sanitaire-ce-nest-pas-possible-de-jouer-avec-lopinion-sur-les-chiffres/

24. Université virtuelle du Sénégal, Interview du Docteur Bousso, consulté le 22 octobre 2020, https://www.uvs.sn/entretien-avec-dr-bousso-premiere-partie/

25. Les moins de 20 ans représentent $50,1 \%$ de la population et que l'âge moyen au Sénégal est de 19 ans. ANSD, Repère statistique de l'environnement d'évolution du covid-19 au Sénégal. Chiffres clé sur la population du Sénégal, consulté le 19 octobre 2020. http://www.ansd.sn/ressources/publications/ Repere\%20statistique\%20covid_N6-population-senegal.pdf

26. "Changement de paradigme sur les ayants-droit au dépistage. Dr Mohamed Ly parle d'une omerta qui ne dit pas son nom ", consulté le 29 juin 2020, http:// www.sudonline.sn/dr-mohamed-ly-parle-d-une-omerta-qui-ne-dit-pas-sonnom_a_48425.html «Gestion de la pandémie de covid-19. Le Dr Mohamed Lamine Ly 
décèle les erreurs et délivre l'antidote » consulté le 9 août https://www.sudonline.sn/ dr-mohamed-lamine-ly-decele-les-erreurs-et-delivre-l-antidote_a_48976.html, «Le covid-19: accalmie ou illusion?» consulté le 8 septembre 2020 https:// blogs.mediapart.fr/mohamed-lamine-ly/blog/080920/covid-19-accalmie-ou-illusion? userid=bea95143-c280-47f2-9f45-ea6143ea368c

27. «Réduction des cas positifs de Covid-19 à Diourbel: Dr Dieng évoque un problème de volume de tests ", consulté le 28 août 2020, https://www.lequotidien.sn/reductiondes-cas-positifs-de-covid-19-a-diourbel-dr-dieng-evoque-un-probleme-de-volume-detests/; « Propagation du virus : des villages sénégalais défient le Covid-19 » consulté le 3 aout 2020, https://www.afrik.com/propagation-du-virus-des-villages-senegalaisdefient-le-covid-19

28. SITREP 46, http://www.sante.gouv.sn/activites/sitrep-46-coronavirus-riposte\%C3\%A0-1\%C3\%A9pid\%C3\%A9mie-du-nouveau-coronavirus-covid-19-

s\%C3\%A9n\%C3\%A9gal-rapport

29. Note circulaire $\mathrm{N}^{\circ} 007337$ du Ministère de la santé et de l'Action Sociale datée du 4 juillet 2020.

30. "Coronavirus : un cas confirmé à Touba, ville sainte de la confrérie mouride au Sénégal », consulté le 12 mars 2020, https://fr.africanews.com/2020/03/12/ coronavirus-un-cas-confirme-a-touba-ville-sainte-de-la-confrerie-mouride-au//

"Au Sénégal, l'ombre du coronavirus plane sur les rassemblements religieux ", consulté le 14 mars 2020, https://www.lemonde.fr/afrique/article/2020/03/13/ senegal-l-ombre-du-coronavirus-plane-sur-les-rassemblements-

religieux_6032893_3212.html

31. "Coronavirus à Touba: Deux personnes mises en quarantaine "s'évadent", consulté le 15 mars 2020 ,

https://www.senenews.com/actualites/coronavirus-a-touba-deux-personnes-misesen-quarantaine-sevadent_301927.html

32. https://www.dakaractu.com/COVID19-A-TOUBA-Des-chiffres-encore-et-toujours-ala-baisse_a191946.html

33. "Covid-19: un cas suspect à Ziguinchor», consulté le 21 mars 2020, https:// thieydakar.net/covid-19-un-cas-suspect-a-ziguinchor/

34. "Covid-19 - Ziguinchor: 1 cas communautaire introuvable depuis mercredi", consulté le 11 juin 2020, https://2stv.net/covid-19-ziguinchor-1-cas-communautaireintrouvable-depuis-mercredi/

35. « un site diagnostique pour cas asymptomatiques à Ziguinchor, consulté le 4 juin 2020, https://www.tract.sn/covid-19-un-site-diagnostique-pour-cas-asymptomatiquesa-ziguinchor/

36. "Coronavirus : La situation s'aggrave à la prison de Ziguinchor ", consulté le 21 juillet 2020, https://www.senenews.com/actualites/coronavirus-les-chosessaggravent-a-la-prison-de-ziguinchor_320847.html

37. «Covid-19/Ziguinchor : " la situation est grave, très grave même » (médecin-chef) » consulté le 6 août 2020, https://gandiayeinfos.com/covid-19-ziguinchor-la-situationest-grave-tres-grave-meme-medecin-chef/ 
38. Arrêté ministériel $n^{\circ} 4532$ mspm-sg-bl en date du 19 juillet 2006 fixant le ressort territorial et la liste des districts sanitaires. Les 4 districts sanitaires du département de Dakar correspondant aux 4 arrondissements fixés par le décret du 10 septembre 2008.

39. Adrian Adams, La terre et les gens du fleuve. Paris, L'Harmatan, 1985, 243 p.

40. Les loumas sont des marchés hebdomadaires. Au cours de ces dernières années ils ont pris une importance considérable:«Soutenant des échanges importants et réguliers fondés sur l'avantage comparatif, les loumas sont en passe de devenir incontournables pour l'approvisionnement des populations aussi bien urbaines que rurales » (Enda Diapol, 2007, Les Dynamiques Transfrontalières en Afrique de L'Ouest, p. 70, CRDI).

41. "Coronavirus-cas importé à Velingara: il s'agit d'une femme guinéenne", Sudestinfo, 25 avril 2020: https://sudestinfo.com/coronavirus-cas-importe-avelingara-il-sagit-dune-femme-guineenne/

42. "Bilan Covid à Vélingara: plus de 100 personnes mises en quarantaine", emedia.sn, 3 mai 2020 : https://emedia.sn/BILAN-COVID-A-VELINGARA-PLUS-DE-100PERSONNES-MISES-EN-QUARANTAINE.html

43. "Coronavirus: l'inquiétude Medina-Gounass", tambacounda.info, 7 mai 2020 : https://www.tambacounda.info/2020/05/07/coronavirus-linquietude-medinagounass/

44. SITREP 16, Rapport de situation du 30 avril 2020.

45. SITREP $11 \mathrm{du}$ et OIM Sénégal Covid-19: https://www.crisisresponse.iom.int/sites/ default/files/appeal/documents/IOM\%20COVID-19\%20SENEGAL\%20Appeal.pdf

46. OIM-Sénégal Covid-19, 2020, Plan stratégie de préparation et de réponse févrierdécembre 2020, consulté le 20 octobre 2020, https://www.crisisresponse.iom.int/sites/ default/files/appeal/documents/IOM\%20COVID-19\%20SENEGAL\%20Appeal.pdf

47. «Pour stopper l'importation de cas de Covid-19: 2 millions aux Jakartamen de Vélingara ", Le Quotidien, 28 avril 2020: https://www.lequotidien.sn/pour-stopperlimportation-de-cas-de-covid-19-2-millions-aux-jakartamen-de-velingara/

48. Arrêté assouplissement de l'Etat d'urgence, 4 juin 2020.

49. «Réouverture des classes au Sénégal : pourquoi l'exécutif a reculé », Jeune Afrique, 2 juin 2020 : https://www.jeuneafrique.com/992619/politique/reouverture-des-classesau-senegal-pourquoi-lexecutif-a-recule/

50. Message à la Nation du Président de la République du Sénégal, Macky Sall, le 29 juin 2020. Levée de l'état d'urgence instauré dans le cadre la lutte contre la maladie COVID-19.

51. https://www.xibaaru.sn/inondationsle-plan-orsec-marche-a-kaffrine-et/.

52. http://dakarshow.com/innondations-kedougou-coupee-du-senegal-les-autoritestoujours-absentes/.

53. https://www.dakaractu.com/Covid-19-Nioro-du-Rip-a-enregistre-37-cas-positifsLe-personnel-de-sante-n-est-pas-epargne-avec-12-agents-contamines_a193179.html. 


\section{RÉSUMÉS}

Cet article interroge les dynamiques temporelles et spatiales de l'épidémie de la Covid19 au Sénégal, en privilégiant un jeu d'échelles d'analyses, à partir des données produites par le Ministère de la Santé et de l'Action Sociale. Une cartographie heuristique révèle la continuité vs discontinuité de la propagation de la Covid-19, mettant en évidence des constats parfois inattendus sur le processus de diffusion de l'épidémie - en milieu urbain et entre l'urbain et le rural - qui dépassent le simple exemple du Sénégal. Cette étude, consacrée à la première vague située entre mars et octobre 2020, éclaire également la gestion de la crise Covid-19, alors que cet État a été donné en exemple, démentant ainsi certains préjugés à l'encontre des États africains.

\section{INDEX}

Index géographique : Sénégal

Mots-clés : Covid-19, épidémie, analyse spatiale, gouvernance sanitaire, cartographie

\section{AUTEURS}

\section{VÉRONIQUE PETIT}

Démographe, UMR 196 CEPED IRD- Université de Paris.

\section{NELLY ROBIN}

Géographe, UMR 196 CEPED IRD - Université de Paris.

\section{NELLY MARTIN}

Géomaticienne, UMR 7301 MIGRINTER CNRS-Université de Poitiers. 